\title{
The Role of Glucocorticoids in Pregnancy: Four Decades Experience with Use of Betamethasone in the Prevention of Pregnancy Loss
}

\author{
Fortunato Vesce, Emilio Giugliano, Elisa Cagnazzo, \\ Stefania Bignardi, Elena Mossuto, Tarcisio Servello and Roberto Marci
}

Additional information is available at the end of the chapter

http://dx.doi.org/10.5772/50797

\section{Introduction}

'Pregnancy loss' can be defined as the failure by the gestational processes to result in the birth of a viable neonate. Miscarriage is defined as the end of pregnancy before the fetus reaches viability, a condition in turn depending on other variables, among which gestational age, birth weight and maturity, as well as the quality of assistance. Therefore to set, as it is done, at 24 weeks the term before which any birth should be classified as abortion is inadequate, because around this time some fetuses survive. On the other hand, preterm birth, that is strictly related with adverse infant outcome in terms of survival and quality of life, is defined as birth at less than 37 weeks. However it will be recognized that while up to the half of the second trimester no foetus at the moment can survive outside the maternal environment, during the third trimester, rather than from gestational age by itself, pregnancy loss will mainly depend on the pathologic condition leading to premature delivery. Recurrent miscarriage refers to the occurrence of three or even two (von Eye Corleta, 2010) consecutive pregnancy losses. The attempt to distinguish sporadic from repeated abortion stems from the believe that they may have different causes. Nevertheless, although it may be difficult to establish the pathogenic mechanism in single cases, in general it is much better understood today, and it is basically always the same: therefore it appears that separating sporadic from recurrent abortion is no longer needed. Indeed, pregnancy loss can occur at any time throughout gestation and labour as a consequence of a number of pathologic conditions widely recognizing two background pathways, namely the impairment of the blood supply to the foetus and the stimulation of uterine contractions. In the majority of the cases, such complications are triggered by an either pre-existent or acquired inflammatory mechanism. For instance, maternal rheumatic diseases represent a well known condition leading to poor pregnancy outcome (Spinillo et al., 2012), although, as 
it will be explained ahead, abortion can also represent the only pathologic expression of functional changes resembling inflammation confined at the uterine mucosa level. At this regard, one basic need in approaching the role of glucocorticoids (GCs) in medicine is represented by a reappraisal to the concept itself of inflammation. This, indeed, based on our background medical education, is characterized by classical signs and symptoms (rubor, calor, tumor, dolor and functio laesa) as well as by several hemato-chemical and histological features. However, the cytokines and prostanoids that trigger inflammation are also involved in the regulation of important physiologic functions, among which social behaviour of cells (Biondi et al., 2006), angiogenesis (Suffee et al., 2011), haemostasis (Salgado et al., 1994) and smooth muscle contraction (Shynlova et al., 2009). In obstetrics, processes such as implantation and labour are under the control of these mediators, the imbalance of which is able to deviate a physiological function towards an inflammatory disease, leading to a wide number of gestational complications, from abortion (Saini et al, 2011) to foetal malformation (Sljivic et al., 2006), intra-uterine growth restriction (Eastabrook et al., 2008), abruptio placentae (Nath et al., 2007), premature delivery (Romero et al., 2002), as well as hyaline membrane disease (Cheah et al., 2005), necrotizing entero-colitis (Xu et al., 2011) and hypoxic ischemic encephalopathy of the newborn (Liu et al., 2010). Such a cytokine and prostanoid imbalance may therefore represent the early change for an eventual, future inflammation. Surprisingly, instead, implantation and labour themselves are often named as a sort of inflammatory process, thus implying that a pathologic event may be beneficial to human health: such a pointless unsafe concept should be better avoided. Indeed, besides its intrinsic contradiction, it represents an obstacle to the liberal use of some anti-inflammatory drugs, among which GCs, aimed at re-balancing the above mentioned mediators for preventing harmful complications. There is a further point of primary significance to be considered before entering into the specific field of pregnancy regulators, and it deals with the causal relationship between inflammation and infection. At this regard, it is generally accepted that it is the latter to trigger the first, while, based on a number of considerations, at least in some cases the opposite is true. Indeed, most bacteria responsible for infection belong to the saprophytic flora, thus suggesting that their shift to pathogen may be a consequence of an environmental alteration, possibly linked with a cytokine-prostanoid imbalance that leads to the inflammatory response. Such a view is strongly supported in obstetrics, thanks to the fundamental work of professor Romero showing that premature delivery, an ominous condition of pregnancy often complicated by infection, is preceded by an inflammation of gestational tissues: 'the foetal inflammatory response syndrome', that will be explained in a more detailed manner ahead. Being, to the best of our knowledge, the Romero's syndrome the first clinical demonstration of a reversed causal relationship between infection and inflammation, it represents a milestone suggesting to search for similar pathogenic mechanisms in other fields of medicine. In the meantime, it opens to debate upon the role and priority of the drugs currently used in the management of such disease, namely GCs, antibiotics and non steroidal anti-inflammatory compounds.

\section{Mediators of physiological pregnancy}

Based on the above considerations, we proceed now to analyze the pro- as well as the antiinflammatory mediators of physiological pregnancy. Cytokines found at the maternal-foetal 
interface include interferons (IFNs), interleukins (ILs), leukaemia inhibitory factor (LIF), tumour necrosis factors (TNFs), transforming growth factors (TGFs), colony stimulating factors (CSFs), vascular endothelial growth factors (VEGFs) and many others (Chaouat et al., 2007). Although a prevalence of pro-inflammatory cytokines are found during the early stages of pregnancy, the action of the anti-inflammatory is needed as well. For instance, LIF and IL-6 are required for a successful implantation in mice (Robb et al., 1998), but the lack of activity of IL-11 results in reduced fertility (White et al.,2004).

With the aim to shed light upon the complex network of reciprocal influences between cytokines and prostanoids from one side and their trophoblastic target form the other, we provide a more detailed description as regards the macrophage migration inhibitory factor (MIF) system, the interleukin-1 system (IL-1), the Toll-like receptors (TLRs) and the chemicals known as "endocrine disruptors" (EDs). (Figure 1).

\subsection{MIF}

The need for a balanced action of cytokines, whether or not of the inflammatory type, is confirmed looking at the macrophage migration inhibitory factor (MIF) system. MIF stimulates the production of a large panel of pro-inflammatory molecules, such as TNF $\alpha$, IFN $\gamma$, IL-1 $\beta$, IL-2, IL-6, IL-8 (Calandra et al., 1995) as well as nitric oxide (NO) (Cunha et al., 1993), matrix metalloproteinases (MMPs) and products of the arachidonic acid pathway (Calandra et al., 2003). MIF protein and mRNA are expressed by first trimester human villous and extra-villous trophoblast, the protein being also found in term placenta, amniotic fluid and maternal serum (Ietta et al. 2002). Their levels are higher at the beginning of first trimester to decline later on. Moreover, they are up-regulated by low oxygen tension, comparable to the values occurring at the very early stage of pregnancy (Ietta et al., 2007). Trophoblast MIF reduces the cytotoxicity of decidual natural killer (NK) cells (Arcuri et al., 2006), and intraperitoneal injection of rMIF to pregnant mice induces an increase of endometrial alpha(v),beta-3-integrin subunits and VEGF expression, that are markers of uterine receptivity (Bondza et al., 2008). Accordingly, pregnant MIF-treated mice show an enhanced rate of implanted embryos with respect to controls (Bondza et al., 2008), although fertility is not impaired in MIF knock-out mice (Fingerle-Rowson et al., 2003).

\subsection{IL-1}

The IL-1 system represents a further regulator of uterine receptivity and embryo implantation At the implantation site, immunoreactive IL-1 $\beta$ was detected in the villous and extravillous trophoblast as well as in the maternal decidual cells (Paulesu et al. 2010). Moreover, interleukin-1 receptor type 1 (IL-1R tI) is expressed by the syncytiotrophoblast, supporting the stimulatory effect of IL-1 $\beta$ on human chorionic gonadotropin (hCG) release (Masuhiro et al., 1991). IL-1 has been reported to stimulate different cytokines in the endometrium, including IL-6, IL-8, LIF and TNF- $\alpha$, as well as the expression of prostaglandins (PGs)-2 and $-2 \alpha$ and their receptor EP1 (Minas et al., 2005). The presence of IL- $1 \alpha$ and IL-1 $\beta$ in the embryo culture medium has been correlated with successful 
implantation after in vitro fertilization (Karagouni et al., 1998). Later studies of endometrial secretions from women before embryo transfer showed the association of lower levels of IL$1 \beta$ with clinical pregnancy (Boomsma et al., 2009). Since IL-1 $\beta$ and TNF $\alpha$ are significantly related to clinical pregnancy and not embryo implantation, it was suggested that these two cytokines are not associated with the initial apposition and adhesion of the embryo (Boomsma et al., 2009). An inappropriate ratio of IL-1 $\beta$ to IL- $\alpha$ and higher IL-1R tI are involved in the establishment of ectopic pregnancy in the oviduct (Huang et al., 2005). IL-1 $\beta$ mediates the paracrine effect of PG synthesis by inducing COX-2 (Pellicer et al., 2002), and IL-1 $\alpha$ induces the production of MMP-1 in stromal fibroblast and raises the activity of MMP9 in trophoblast (Pellicer et al., 2002). Moreover, it has been shown that trophoblast reduces the secretion of pro-inflammatory cytokines IL-1 $\beta$, IL- 6 and TNF $\alpha$ elicited by low (0.1 $\mu \mathrm{g} / \mathrm{mL}$ ), but not high, doses lipopolysaccharide (LPS)-activated monocytes (Fest et al., 2007). As the female genital tract is opened to the external environment, cytokine release by gestational tissue can be influenced by external factors. For instance, exposure to seminal plasma factors including TGF $\beta 1$ stimulates cytokine production by uterine epithelial cells, with consequent recruitment and activation of macrophages, granulocytes and dendritic cells in the underlying stroma (Gopichandran et al., 2006).

\subsection{TLRs}

Cytokine release by gestational tissue is further regulated through the action of specific receptors for pathogen-associated molecular patterns, named Toll-like receptors (TLRs). These are present in the epithelial lining as well as in the underlying connective stroma of the human female reproductive tract (Hirata et al., 2007). TLR2 and TLR4 have been detected in villous and extra-villous, but not in syncytial first trimester trophoblast, TLR6, instead, is absent in the first but present in the third trimester trophoblast (Mitsunari et al., 2006). Binding of TLRs with microbial antigens activates the release of pro-inflammatory cytokines, possibly interfering with their physiological gestational balance (Schaefer et al., 2005). In addition to the above mentioned factors, also stress, nutrition, metabolic status, drugs and environmental chemicals (Arck et al., 2008), as well as genetic conditions are known to influence gestational cytokine and prostanoids.

\subsection{EDs}

Some chemicals defined as "endocrine disruptors" (EDs) are able to act like natural estrogens, interfering with reproductive processes. For instance, it has been recently shown that the ED para-nonylphenol (p-NP) affects trophoblast cytokine secretion as well as cell differentiation and apoptosis (Bechi et al., 2010). In addition to cytokines and prostanoids, also the cellular components of the immune system are involved in the regulation of physiological pregnancy. Among these, NK cells, that are large granular lymphocytes constituting $10-15 \%$ of their total circulating number. Even though their main activity is citotoxicity of target cells, in normal pregnancy they provide benefit by secreting cytokines, chemokines and angiogenetic factors which are needed for pregnancy success (Santoni et al., 2008). There is a further class of NK at the decidual level, named uterine NK (uNK), which 
are provided with phenotypic markers different from peripheral ( $\mathrm{pNK})$. uNK cells seem to be necessary for pregnancy success by producing factors that modulate trophoblast invasion and placental vascularization (Saito et al., 1993).

All above evidences outline the concept that there is no single substance, or mediator, or cell type that can be specifically identified as either detrimental or protective towards physiological pregnancy, but rather that it is their imbalance which can lead to an unfavourable outcome.
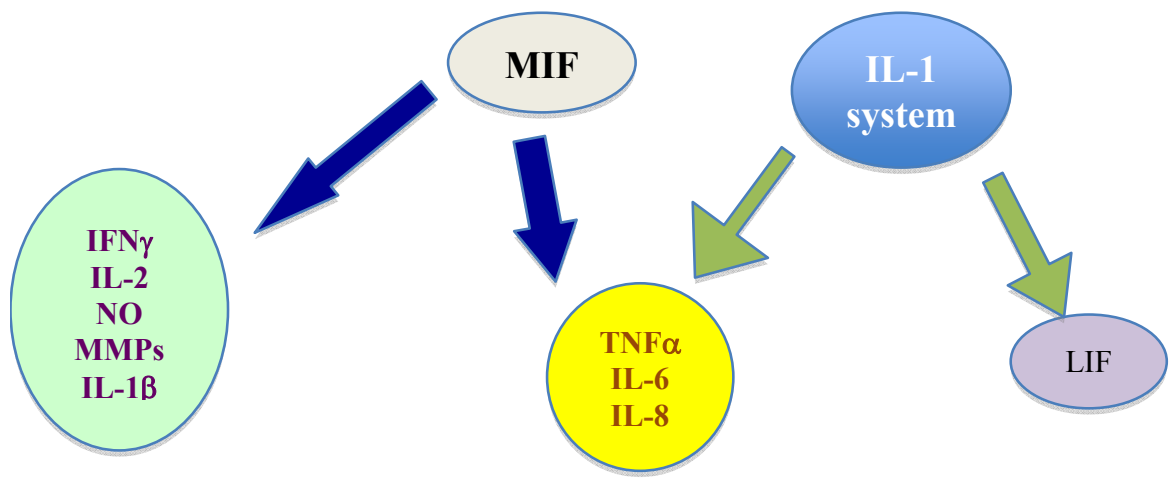

Figure 1. Influences of MIF and IL-1 systems on cytokine network in physiologic pregnancy

\section{Hormone regulation of gestational cytokines and prostanoids}

Pregnancy can be defined as a vascular phenomenon under the control of steroid hormones. Indeed nearly all above mentioned mediators are directly or indirectly able to interfere with the maternal uterine arteries changes aimed at increasing the foetal blood supply, and they are largely influenced by steroids. Therefore we will look now at the experimental results supporting the specific role of estrogen, progesterone and glucocorticoids in the control of the mediators of gestational functions. In particular, as progesterone and glucocorticoids actions are higly impaired by the abortive drug named mifepristone, we will compare influence of such compounds upon some gestational regulators and functions. Such a comparison should better address to understand the nature of both hormonal protection and drug impairment of pregnancy, provided that their action mechanisms lead to opposite regulatory consequences.

\subsection{Estrogen and progesterone}

Estradiol and progesterone exert an important role in the regulation of a number of the factors involved in gestational processes thus avoiding harmful inflammatory response (Dekel et al., 2010). By doing so, these hormones also modulate epithelial cells ability to respond to pathogenic microbes. Indeed estradiol suppresses the secretion of MIF, TNF $\alpha$, IL-6 and IL-8 induced by bacteria in the uterine epithelial cells (EEC-1) (Wira et al., 2010). 
Moreover the hormone stimulates IL-1 $\beta$ secretion in LPS-activated human uterine monocytes and down-regulates protein-expression of IL-1RtI, thus inhibiting the IL-1 $\beta$ mediated inflammatory response. In chorionic explants MIF secretion is dose-dependently modulated by $17 \beta$-estradiol (E2) (Ietta et al., 2010). As for progesterone, it favours the secretion of IL-3, IL-4, IL-5 and IL-10, that are reported to inhibit the Th1 response (Pioli et al., 2006). Interestingly, however, dydrogesterone induction of a Th1 to Th2 cytokine shift is also expressed by inhibition of IFN- $\gamma$ and TNF- $\alpha$ but up-regulation of the production of IL-4 and IL-6. It happens therefore that, given a protective action of progesterone against abortion, IL6, that is able to trigger PG release, thus leading to abortion or premature delivery, being up-regulated by the hormone, should be considered protective in the context of early pregnancy! (Raghupathy et al., 2005).

\subsection{Mifepristone}

The complexity of the relation between cytokine balance and pregnancy outcome is further expressed by comparison of mifepristone (Ru486), betamethasone and progesterone action mechanisms. As for the antiprogestational action of Ru486, the mechanism by which it inactivates the progesterone receptor (PR) is not completely clarified (Leonhardt et al., 2002). However it appears that its abortive action could be in some way related with an influence on cytokines, as repeated administration of the drug significantly enhances the serum production of TNF $\alpha$ and IFN $\gamma$ while prolonging LPS-induced depressive-like behaviour in rats (Wang et al., 2011), although it does not exert the same effect in mice (Yang et al., 2008). RU486 also stimulates the expression of IL- 6 and LIF protein in human villous trophoblast and stroma cells in early pregnancy, thus questioning the supposed IL6 protective role (Pei et al., 2010). Indeed, while opening to debate the action mechanism of progestogens, GCs and their antagonists at the level of gestational tissues, such contradictory observations do not clarify (whether or not inflammatory) the role of IL6 in pregnancy. RU486 counteracts the hyper-polarization of cell membranes as well as the inhibition of gap-junctions responsible for uterine contraction exerted by the hormone (Garfield et al., 1988). It also stimulates the release of PG and impairs the PG-dehydrogenase activity (Norman et al., 1991). As a consequence, the uterine sensibility to PG is significantly enhanced. Accordingly, the capacity of the drug alone to induce abortion is low, while it raises up to $95 \%$ when followed by PG administration (Grimes, 1997). Therefore, once again, it appears that early abortion of an otherwise normal pregnancy is mainly obtained by smooth muscle contraction (and therefore by impairment of utero-placental blood perfusion), rather than by a disturbance of the cellular mechanisms of implantation. However, the antiglucocorticoid nature of RU486 is also well characterized. Indeed, it binds to the glucocorticoid receptor (GR), and oral administration of the drug results in a dose-dependent activation of the hypothalamic-pituitary-adrenal (HPA) axis (Gaillard et al., 1984). Despite the compensatory increase in the serum cortisol concentration, in patients undergoing medical termination of a first trimester pregnancy the net effect of this compound is a profound suppression of circulating GC bioactivity (Heikinheimo et al.; 2003). Given the power of the anti-GC activity of RU486, the question arises whether its abortive action is also due to this property. 
Furthermore it is interesting to ascertain whether such an action is to be ascribed to the disturbance of intercellular communication at the earliest stage of blastocyst implantation or to impairment of blood perfusion later on. Indeed, among the potentially positive effects of GC in early pregnancy, promotion of trophoblast growth and invasion have been suggested, along with stimulation of hCG secretion and suppression of NK cells (Michael \& Papageorghiou; 2008). By modulating extravillous trophoblast proliferation and invasion, in fact GC may directly influence the capacity of chorionic villi to modify the structure of maternal spiral arteries, a change aimed at meeting the needs of embryo oxygenation and growth. The initial process of invasion belongs to the cross-talk between trophoblast and uterine decidua. Blastocyst attachment appears to be regulated by cell surface signalling molecules among which integrins and fibronectin. At physiological concentrations (100 nmol/l), GCs can suppress the expression of trophoblast integrins while their effects on fibronectin expression are tissue-specific (Burrows et al., 1996). For instance, in human pregnancy at term, dexamethasone suppresses fibronectin expression cytotrophoblasts and amnion while it acts in synergy with transforming growth factor-b towards up-regulation in matched samples of chorion and placental mesenchymal cells (Guller et al., 1995). Moreover, trophoblast functions are regulated by gap-junctional intercellular communication (GJIC) (Malassiné \& Cronier, 2005). Gap junctions (GJ) are membrane channels which span the intercellular space, providing a pathway for the exchange of signalling molecules such as second messengers and siRNA. Said channels are constituted by the association of two hemi-channels, termed connexons, each composed of six connexin (Cx) subunits. Trophoblast Cx expression is modulated by hCG and estradiol, and GCs have been shown to enhance trophoblast GJIC in human pregnancy at term (Cronier et al., 1998). We have recently demonstrated that betamethasone selectively modifies trophoblast GR and Cx expression, enhancing the GR $\alpha$ isoform without affecting GR $\beta$, and inhibiting $\mathrm{Cx} 40$ expression while increasing that of $\mathrm{Cx} 43$ and 45. Furthermore, betamethasone exerts an inhibitory action on cell proliferation. This result could be at least partly due to the inhibitory effect of the reduced expression of Cx40, coupled with an upregulation of Cx43. Indeed, it has been reported that $\mathrm{Cx} 40$ is involved in trophoblast proliferation (Winterhager et al. 1999; Nishimura et al. 2004), and that Cx43 upregulation is associated with an inhibition of JEG-3 cell proliferation (Kibschull et al. 2008). By modulating extravillous trophoblast proliferation and invasion, GCs may directly influence the capacity of chorionic villi to modify the structure of maternal spiral arteries, a change aimed at meeting the needs of embryo oxygenation and growth.

RU-486, in spite of its anti-GR property, does not contrast this effect of betamethasone. On the contrary, it induces responses similar to those of the hormone. As for progesterone, it shows the same effect as betamethasone on Cx expression, while it does not affect proliferation. RU-486 does not antagonize the progesterone effect as well. These results, by confirming that neither the abortive action of RU486 nor the protective action of GCs are obtained through their influence on trophoblast $\mathrm{Cx}$ expression, along with the other above mentioned evidences, do not exclude that the abortive mechanism of the drug may be also linked to its anti-glucocorticoid action at a level other than Cx (Cervellati et al., 2011). 
Moreover, as for the nature of the events leading to pregnancy loss, it appears that it is not to be ascribed to the disturbance of intercellular communication at the earliest stage of blastocyst implantation, but rather to the impairment of blood perfusion and triggering of uterine contractions obtained through an intensive prostaglandin administration later on. If the enhanced responsiveness of myometrium to prostaglandins, that represents the main abortive action of mifepristone, derives from the anti-progesterone or anti-GCs effects, or even both or none of them, remains to be ascertained.

\subsection{Influence of GCs on TLR and MIF}

Further examples of the regulatory actions of GCs are down-regulation of TLR expression, suppression of pro-inflammatory and up-regulation of anti-inflammatory cytokines by dexamethasone in primary isolated murine liver cells (Broering et al., 2011), as well as inhibition of the human pro-IL-1 $\beta$ gene by decreasing DNA binding of transactivators to the signal-responsive enhancer (Waterman et al., 2006). It is interesting to observe that the GR can be influenced even independently from GCs. Indeed the unliganded GR attenuates TNF- $\alpha$ stimulated IL- 6 transcription by a mechanism involving selective phosphorylation and recruitment of the unliganded GR and GRIP-1 to the IL-6 promoter. It is suggested that such an autoregulatory mechanism may prevent overproduction of IL-6 in the endocervix, possibly protecting against negative effects of excessive inflammation (Verhoog et al., 2011). However GCs are also reported to induce, rather than to inhibit, the secretion of MIF (Calandra et al., 1995), thus counteracting the hormone inhibition of pro-inflammatory cytokine production. Such an influence is an example of particular relevance in understanding the nature of a balanced protective action against pregnancy loss.

\subsection{Trans-placental passageand action site of GCs}

A further matter of debate is represented by the regulation of GCs passage into the foetal

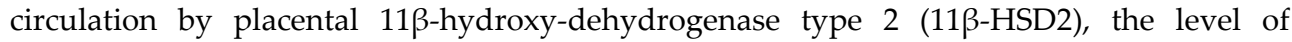
expression and activity of which is determined by a delicate balance between stimulatory and inhibitory influences. Studies of human and other primate placentas or derived trophoblast cells have shown that placental $11 \beta$-HSD2 activity is reduced by progesterone, estrogen, NO, PGs, proinflammatory cytokines and infections, $\beta$-adrenoceptor agonists, hypoxia and peroxisome proliferator-activated receptor $\delta$ agonists. Conversely, placental $11 \beta$-HSD2 activity is stimulated by GCs, retinoids and activators of the pathway that includes cyclic AMP and protein kinase A (Seckl et al., 2007). Moreover, the exposure of foetal tissues to cortisol may be determined locally by $11 \beta$-HSD isoenzymes within the foetus, rather than simply by GC metabolism at the materno-fetal interface (McNeil et al., 2007). In the trophoblast cells, (the most abundant site of 11 $\beta$-HSD1), cortisol up-regulates enzyme expression inducing promoter activity, and the effect is enhanced by IL-1 $\beta$. This suggests that more biologically active GCs could be generated in the foetal membranes in the presence of infection, which may consequently feed forward in up-regulation of PG synthesis. Intriguingly, foetal membranes are a major site of PG synthesis during pregnancy 
(Li et al., 2006), the production of which has been reported to be increased by GCs (Sun et al., 2003). However, such stimulatory actions of GCs on the biosynthetic pathways of PG, rather than simply suggesting adverse clinical outcomes, sharpen the complexity of the hormonal regulatory influence upon the internal homeostasis of organic functions, as they, as it will be said ahead, adequately administrated, ultimately contribute to shift the complicate network of cytokines and prostanoids towards a beneficial direction. All above evidences indicate nothing more than the regulation of gestational processes to rely upon an extremely high number of mediators under physiological hormonal control, that are influenced by both maternal and foetal conditions (either congenital or acquired), as well as by external factors able to modify utero-placental perfusion and myometrial quiescence. As pregnancy loss can occur at any time during gestation and labour, it follows that the outcome of pregnancy will depend on the grade and time of the regulators derangement. In other words, speaking of pregnancy loss, there is no difference between the pathogenic mechanism of abortion and that of premature delivery, other than the first to happen very early, the second at a time when the foetus may have already reached the capacity to survive.

\section{Direct and indirect relationship between inflammation and pregnancy loss}

Aetiology of pregnancy loss includes chromosomal, anatomical, hormonal, immunological and endocrinological abnormalities, but in most cases the cause remains unexplained. It is frequently claimed that an inflammatory microenvironment is required for adequate tissue remodelling during implantation and the early phase of pregnancy (Challis et al., 2009). On the contrary, the second trimester is characterized by a prevalence of anti-inflammatory signals. An inflammatory pattern is then required near term of pregnancy to induce labour contractions and cervical dilatation (Paulesu et al., 2010). At this regard, for instance, we have demonstrated the presence on human amnion-derived WISH cells of binding sites for formyl-methionyl-leucyl-phenylalanine (fMLP), the classical chemotactic receptor for $\mathrm{N}$ formyl peptides. fMLP induces a significant increase of PGE2 release by these human amnion-derived cells. Such a response in turn is impaired by COX, phospholipase A2, and phospholipase C inhibitors (Biondi et al., 2001). Furthermore we have shown that labouring amniotic membranes express both high- and low-affinity specific receptors for 3H-fMLP, while only the low-affinity are found in non-labouring tissue, and that the peptide is able to significantly increase PG synthesis in perifused amnion fragments from labouring and nonlabouring women. (Buzzi et al., 1999). Nevertheless, abnormal inflammatory events may lead to adverse pregnancy outcomes, such as implantation failure, pregnancy loss, preeclampsia, preterm labour, intrauterine growth restriction (IUGR), and foetal inflammatory syndrome (Kwak-Kim et al., 2010). Disregulation of cell function mediators can simply derive from genetic conditions, with no need for infectious or inflammatory external stimuli. Indeed, it has been reported that polymorphisms in immunoregulatory genes IL10, MBL2, TNFRSF6 and TGFB1 may influence susceptibility to chorioamnionitis (Annells et al., 2005), and common genetic variants in proinflammatory cytokine genes, such 
as some selected TNF/LTA haplotypes, increase the risk for spontaneous preterm birth (Engel et al., 2005).

\subsection{The Th1/Th2 paradigm}

It has been suggested that a successful pregnancy may be a Th2 type phenomenon, whereas a Th1-type prevalence could be detrimental (Kwak-Kim et al., 2003). Immune regulation of pregnancy is mediated by TH1, TH2 and macrphages throughout the release of a number of cytokines (Table 1). Women with recurrent pregnancy loss have higher peripheral concentrations of certain Th1 cytokines (IL-2, TNF- $\alpha$, TNF- $\beta$, IFN- $\gamma$ ) and lower concentrations of Th2 (IL-4, -5, -6, -10) when compared with successful pregnancy. Th1 cytokines, especially IFN- $\gamma$, may activate endothelial cell procoagulants and cause thrombotic and inflammatory reactions at the utero-placental level (Clark et al 1998). As for the mechanism by which thrombotic changes are induced, it has been reported an increased expression of pro-coagulant Fg12 in trophoblast cells from failing pregnancy (Knackstedt et al., 2001). Fg12 is a glycoprotein able to directly cleave prothrombin to thrombin, leading to fibrin deposition. Th1 cytokines up regulate this procoagulant, with consequent activation of the coagulation system and disruption of vascular supply to the placenta. On the contrary, Th2 system can hamper this process, suppressing Th1 response (Saini et al., 2011). Among proinflammatory cytokines, TNF- $\alpha$ is of particular interest. Indeed, even though a low concentration is required for successful implantation, it also causes trophoblast apoptosis in combination with Th1 cytokines such INF- $\gamma$. The cytokine could even be involved in pregnancy loss by impairing utero-placental perfusion. A recent study on mouse (Renaud et al., 2011) reported a causal link between maternal inflammation induced by LPS administration and impaired placental perfusion. LPS administration determined a disseminated intravascular coagulation(DIC)-like condition, with clot formation within uterine vessels, decreased diastolic uterine artery flow velocity and evidence of prominent diastolic notches, resulting in placental and foetal hypoxia. Many biological effects of LPS are mediated by TNF- $\alpha$. Oppositely, IL-10 administration decreased serum level of TNF- $\alpha$, preventing pregnancy loss after LPS exposure. Cytokines of the IL- 1 system (IL- $1 \alpha$, IL- $1 \beta$ and IL-1 receptor antagonist) are an important regulatory element of the Th1/Th2 balance. They have been implicated in implantation, and trophoblastic cells proliferation and invasion (Wang et al., 2002). On the other hand, it is interesting to note that IL-1 system can also function as a co-stimulator for Th2 response. Therefore, altered decidual IL-1 $\beta$ production may cause a reduction in Th2-type cytokine production, contributing to early pregnancy failure. The Th1/Th2 paradigm has recently been expanded into the Th1/Th2/Th17 and Treg (T regulatory cells) one (Peck et Mellins, 2010). Indeed increased peripheral and decidual levels of Th17 cells and their related factors (IL-17, IL-23 and retinoid orphan nuclear receptor (RORC) have been reported in women with unexplained recurrent spontaneous abortion (RSA) (Wang et al., 2010). In addition, an inverse relationship between Th17 cells and Treg cells in the peripheral blood and decidua lymphocytes in unexplained RSA has been found. Treg cells are defined by secretion of TGF- $\beta$ and IL10 and the presence of intracellular transcription factor FoxP3. Studies in 


\begin{tabular}{|c|c|c|}
\hline Cells & Cytokine & Actions \\
\hline TH1 & $\begin{array}{l}\text { IFN } \gamma \\
\text { IL1 } \\
\text { IL2 } \\
\text { TNF } \beta \\
\text { TNF } \alpha\end{array}$ & $\begin{array}{l}\text { - Inflammatory reactions } \\
\text { - Thrombotic events through up-regulation of } \\
\text { - Trophoblastic apoptosis, inhibition of } \\
\text { trophoblast cell growth and metabolic activity } \\
\text { - Promotion of syncytium formation and } \\
\text { invasive capacity of trophoblast (TNF } \alpha)\end{array}$ \\
\hline TH2 & $\begin{array}{l}\text { IL4 } \\
\text { IL5 } \\
\text { IL6 } \\
\text { IL10 } \\
\text { TGF } \beta \\
\end{array}$ & $\begin{array}{l}\text { - Anti-inflammatory action } \\
\text { - } \\
\text { Enhancement of hCG secretion } \\
\text { Stimulation of growth and differentiation of } \\
\text { trophoblast }\end{array}$ \\
\hline Macrophage & $\begin{array}{l}\text { IL1 system (IL1 } \alpha, \text { IL1 } \beta, \\
\text { IL1ra) } \\
\text { LIF }\end{array}$ & - Stimulation of trophoblast differentiation (LIF) \\
\hline
\end{tabular}

Table 1. Immune regulation of pregnancy.

animal models (Thuere at al., 2007) have shown that Treg cells are essential for maternal tolerance of the conceptus, and that they exert suppressive actions in the peri-implantation phase. In women, inadequate number of Treg cells or their functional deficiency are linked with infertility, miscarriage and pre-eclampsia (Guerin et al., 2009). It is suggested that impaired Treg function could lead to increased Th1 cytokines (Jin et al., 2009). Nevertheless there are conflicting reports regarding the inflammation state in early pregnancy loss, suggesting adequate balance for Th1/Th2 cytokines, although with a slight shift toward Th2 immunity in successful pregnancy (Saini et al., 2011). A recent study (Calleja-Agius et al., 2012) confirmed an inflammatory state (higher pro-inflammatory cytokines) in normal pregnancy compared with the non pregnant state, which may be disrupted during miscarriage. The study revealed in euploid miscarriage a shift toward Th1 immune response (higher TNF- $\alpha /$ IL-6 ratio) at 6-9 weeks, but a lower TNF- $\alpha /$ IL 10 and IFN- $\gamma /$ IL10 ratios in the late first trimester compared to normal pregnancy. At this regard it must be noted that the classification of IL-6 remains controversial, as some authors consider it as a Th2 mediator due to its anti-inflammatory properties possibly involved in new vessels generation and tissue remodelling associated with placentation (Jauniaux at al., 1996). A further evidence for an influence of inflammatory mediators in pregnancy is represented by the behaviour of maternal serum MIF (Yamada et al., 2002). Indeed, MIF concentrations in recurrent abortion women with subsequent miscarriage and normal foetal karyotype were lower than those in women with history of RSA with subsequent live birth and those in normal pregnant women. Moreover, MIF acts as an immunosuppressive factor by inhibiting NK cell activity. Since women with RPL and unexplained infertility have increased peripheral blood NK cells and increased NK cytotoxic activity (Yamada et al., 2001), low levels of MIF could lead to insufficient inhibition of NK cell activity and altered cytokines production with impairment of trophoblast proliferation, embryo development, and angiogenesis within placenta. One 
more pathway leading from inflammation to pregnancy loss acts via the complement system that induces recruitment and activation of inflammatory cells. Antiphospholipid (aPL) antibodies are able to trigger complement system response within decidual tissue, thus inducing inflammation and foetal damage (Salmon \& Girardi, 2008). Recruitment of inflammatory cells creates a placental proinflammatory amplification loop, eventually leading to thrombosis, hypoxia, and neutrophil infiltration. Accordingly, increased complement activation is associated with recurrent abortion pre-eclampsia and IUGR (Tincani et al., 2009). A pathogenic mechanism has been postulated for recurrent abortion involving NK cells (Laird et al., 2003). Several studies reported a higher concentration of uNK and pNK as well as a higher proportion of activated pNK in women with history of RSA (Radysh \& Chernyshov, 2005).

\section{Classical treatment and drugs for preventing pregnancy loss}

\subsection{Progesterone}

Progesterone is secreted by the corpus luteum and the placenta and is necessary for successful implantation and eventually the maintenance of pregnancy. Progesterone is prescribed in $13-40 \%$ of women with threatened miscarriage, according to published series because it is expected to support a potentially deficient corpus luteum and induce relaxation of a cramping uterus (Rai \& Regan, 2006). This benefit of the hormone could be explained by its immmunomodulatory actions in inducing a pregnancy-protective shift from proinflammatoryTh-1 cytokine responses to a more favourable anti-inflammatory Th-2 cytokine response (Raghupathy et al., 2009). The first trial using progesterone for such women was published in the BMJ in 1953 (Swyer \& Daley, 1953) and was followed over the decades by several small trials. However, uncertainty remains about the evidence. The latest randomized controlled trial (Haas \& Ramsey, 2008) to assess progesterone support for pregnancy showed that it did not reduce the sporadic miscarriage rate. However, in a subgroup analysis of trials involving women with recurrent miscarriage, progesterone treatment appeared to offer a statistically significant decrease in miscarriage rate compared with placebo or no treatment (OR $0.38,95 \%$ CI $0.2-0.7$ ). Nevertheless, in order to understand the limited clinical utility of the conclusions derived from some sort of statistical analysis, it is to be noted that this meta-analysis was based on three small controlled studies, none of which detected a significant improvement in pregnancy outcome! A large multicenter study (PROMISE) is currently under way to assess the benefit of progesterone supplementation in women with unexplained recurrent miscarriage. The trial is expected to report in 2013. At present, progesterone administration is not recommended for unexplained recurrent miscarriage (Coomarasamy et al., 2011).

\subsection{Aspirin}

Aspirin is largely used in pregnancy because it is believed to increase blood flow to the embryo, act on unrecognized thrombophilias and prevent miscarriage. Pregnancy itself is a 
hyper-coaguable state associated with increased levels of procoagulant factors and decreased levels of naturally occurring anticoagulants such as protein S (Comp et al., 1986). Microthrombi are a common finding in the placental vasculature of women with recurrent miscarriage (Rushton, 1988). PGs appear to be essential for implantation, although and exogenous administration of high doses induces abortion: the maintenance of pregnancy may be dependent on a mechanism that suppresses prostaglandin synthesis. Aspirin, which suppresses COX, has the potential to support this mechanism. Moreover, the maintenance of pregnancy is said to depend on a shift of pro-inflammatory to anti-inflammatory cytokines. At this regard, aspirin and other antiplatelet agents have been shown to play a role in the inhibition of pro-inflammatory cytokines, such as TNF $\alpha$ and IL-8. In stroke (Al-Bahrani et al., 2007), TNF $\alpha$ induces thrombin generation and IL-8 causes polymorph accumulation (Schraufstatter et al., 2003). Polymorphs react with fibrin and damaged tissues to form clots. However, at present, no report in the medical literature confirms a role for aspirin in preventing recurrent pregnancy loss. Furthermore, it doesn't confer a significant benefit in anti-phospholipid (aPL) syndrome (Pattison et al., 2000) even if the live birth rate increases significantly when heparin is added to treatment. The syndrome is assumed to be responsible for pregnancy loss by causing thrombosis in the small blood vessels of the decidua, leading to subsequent foetal demise. In unexplained pregnancy loss, aspirin had no beneficial effect except for in late pregnancy losses, in cases where hereditary thrombophilias were not excluded. Since there is no study of aspirin in this condition, it's suggested that the positive effects in advanced pregnancy may be due to the action of the drug in such patients (Rai et al., 2000). Nevertheless, the lack of the evidence of any efficacy against RSA, coupled with a reported increased risk of miscarriage and foetal gastroschisis, contraindicate prescribing aspirin in early pregnancy (Carp HJ, 2009).

\subsection{COX inhibitors}

COX inhibitors impair uterine contractility, are easily administered and have fewer maternal side-effects compared to conventional tocolytics. However, they are not devoid of adverse effects on the foetus and newborn. Indeed, increased neonatal complications including oligohydramnios, renal failure, necrotizing enterocolitis, intraventricular haemorrhage, and closure of the patent ductus arteriosus have been reported with the use of the non-selective COX inhibitor indomethacin (Abou-Ghannam et al. 2011). A recent review includes outcome data from 13 trials for a total of 713 women. with use of indomethacin in 10. When compared with placebo, indomethacin alone resulted in a reduction in birth before 37 weeks gestation, with an increase in gestational age and birth weight. Compared to any other tocolytic, COX inhibition resulted also in reduced maternal drug reaction requiring cessation of treatment. A comparison of non-selective COX inhibitors versus any COX-2 inhibitor did not demonstrate any difference in maternal or neonatal outcomes. However, due to small numbers, all estimates are imprecise and need to be interpreted with caution. Overall, until now there is insufficient information about the role of COX inhibition for women in preterm labour (King et al., 2005). 


\subsection{Antibiotics}

As for antibiotics, their role against infection of the chorioamnionic membranes in preterm labour has been extensively investigated. In these cases, the mechanism by which uterine contractions take place is supposed to be the release of microbial products into the amniotic fluid (Gibbs et al., 1992). There seems to be substantial agreement on the efficacy of antibiotic therapy in the prevention of preterm delivery when there is evidence of infection (Kirshbaum T, 1993), but its utility in idiopathic preterm labour is controversial (Cox et al., 1996). Nevertheless, antibiotics can have beneficial influences not only for their antimicrobial properties but also through a direct tocolytic action on tissues. Indeed, as it will be explained ahead, some among them have the capacity to directly inhibit amniotic IL6 and PGE2 release, thus offering an explanation for a beneficial response in cases of preterm labour even in the absence of bacterial infection. (Vesce et al., 1998;2004).

\subsection{Heparin}

Successful pregnancy depending on trophoblast invasion into the uterine vasculature, inadequate placentation and damage to the spiral arteries with impaired flow and prothrombotic changes lead to pregnancy complications that become even more dangerous in hyper-coagulable states. Such complications benefit from prophylactic low molecular weight heparin (LMWH) and unfractionated heparin (UFH), in spite of several drawbacks to their use, including the costs, discomfort of daily injections, risks of bleeding, skin reactions, and thrombocytopenia (Howard, 2009). Indeed, there is general agreement that women with recurrent loss and persistent aPL antibodies positivity should receive antepartum prophylaxis with UFH or LMWH in combination with aspirin (Bates et al., 2008), while, at present, it is claimed that antithrombotic therapy should not be advocated for unexplained recurrent miscarriage in women without an underlying thrombophilia. (Clark et al., 2010). However, although a protective effect in women with heritable thrombophilia is not to be excluded, the British Committee for Standards in Haematology has recently recommended against the antithrombotic therapy in pregnant women with a history of loss based on the results of testing for inherited thrombophilia (Baglin et al., 2010). Low-molecular-weight instead of unfractionated heparin is recommended for the prevention and treatment of venous thromboembolism in pregnant women (Guyatt et al., 2012). In acute cases, anticoagulants should be continued for at least 6 weeks postpartum, for a minimum total duration of the therapy of 3 months. For women who fulfil the laboratory and clinical criteria for aPL antibodies syndrome and history of three or more pregnancy losses, is recommended antepartum administration of prophylactic or intermediate-dose UFH, or prophylactic (LMWH), combined with low-dose aspirin (75-100 $\mathrm{mg} / \mathrm{d}$ ) over no treatment. For women with inherited thrombophilia and a history of pregnancy complications, as well as for those with two or more miscarriages, but without aPL antibodies syndrome or thrombophilia, it is recommended against antithrombotic prophylaxis. (Guyatt et al., 2012). 


\subsection{Immunotherapy}

Idiopathic recurrent miscarriage has traditionally been associated with alloimmune factors, in which uterine CD56+/16 NK cells have been implicated (Quenby et al., 1999). In vitro studies suggest that pregnancy may result in uterine T-cell activation along the Th-2 pathway, resulting in blocking antibodies which mask trophoblast antigens (Wegmann et al., 1993). Activation along the Th-1 pathway, instead, results in the production of abortive cytokines (Raghupathy et al., 2000). Maternal HY-restricting HLA class II alleles are associated with a decreased chance of a live birth in women with secondary recurrent miscarriage with a firstborn boy (Nielsen et al., 2009). Although such mechanisms are intriguing, there is a paucity of validated tests to assess the maternal immune response in pregnancy. Despite this, active and passive immunotherapeutic trials for idiopathic recurrent miscarriage have been reported. Paternal mononuclear cell immunization has been proved not to be effective (Scott, 2003). It is believed that passive immunotherapy with intravenous immunoglobulin (IVIG) may offer benefit in idiopathic secondary (at least one prior ongoing pregnancy), but not idiopathic primary (no prior ongoing pregnancy) recurrent miscarriage (Christiansen et al., 2002). However, such conclusions must be taken with caution because of small heterogeneous sample size. Moreover, IVIG is a highly purified and virally inactivated fractionated blood product made from pooled human plasma, which makes it costly to use and not without risk. Overall, the efficacy of IVIG in women with a history of idiopathic secondary recurrent miscarriage remains controversial, as no significant effect of treatment in these patients was found (Stephenson et al., 2010).

\section{Influence of glucocorticoids on foetal development}

\subsection{Prenatal administration of GCs and HPA function}

Several studies in animals have shown that prenatal administration of GCs can cause hormonal changes in the foetus. Epidemiologic research in human even suggested that these may have long-term consequences on health in adult life. This concept is termed 'early life programming' (Seckl, 2004). Great importance is given to the influence of GCs on foetal HPA axis. Several studies assessed basal HPA function in the feto-placental unit by measuring markers of its activity in cord blood and amniotic fluid during gestation and at birth. Compared with unexposed healthy foetuses, cortisol concentrations were significantly lower in otherwise healthy foetuses exposed to synthetic GCs, with values decreasing to the $10 \%$ of the controls. These results, however, refer to premature foetuses, which receive 24 mg betamethasone within 24 hours before being delivered (Kajantie et al., 2004). In foetuses of asthmatic mothers who refrained from taking synthetic GCs during pregnancy, cortisol concentrations were even higher compared to those of healthy controls (Murphy et al., 2002). As for placental CRH mRNA, it was slightly higher in asthmatic patients not treated with synthetic GCs. However, treated cases exhibit normal levels irrespective of the treatment dose. Similar to cortisol, ACTH, DHEA and DHEA-S (Parker et al., 1996) concentrations were reduced in treated foetuses. 


\subsection{Metabolic changes induced by prenatal GCs}

The alteration of the HPA activity seems to be closely related to the changes in glucose homeostasis and obesity. In rodent models, administration of dexamethasone leads to permanent hyperglycaemia and hyperinsulinaemia in the offspring (Nyirenda et al., 1998) with life-long elevations in the activity of phosphoenolpyruvate carboxykinase (PEPCK), the enzyme involved in gluconeogenesis. This metabolic effect is correlated with the exposure time, and week 3 of gestation appears to be a critical window for inducing long-term metabolic changes. Similar alterations of glucose homeostasis have been reported in both sheep and non-human primates (de Vries et al., 2007). Although the molecular mechanisms underlying these changes in offspring glucose metabolism have not been fully clarified, the alterations in HPA activity are certainly implicated, as the animals have increased levels of circulating corticosterone, decreased GR expression in the hippocampus, the site of central negative feedback, and increased peripheral GR expression in insulin-sensitive target tissues including liver and muscle in the rat (Nyirenda et al., 1998; Cleasby et al., 2003). The increased PEPCK expression is regulated by transcription factors, including members of the HNF (hepatocyte nuclear factor) and GR that bind to the PEPCK gene promoter. The expression of these factors is increased in liver of rats treated with dexamethasone (Nyirenda et al., 1998), suggesting that the observed increase in PEPCK may be a secondary effect. Thus, changes in key transcription factors may underlie permanent changes in glucose metabolism. The influence of prenatal GCs is also expressed in the foetal pancreas. GC signalling is important in pancreatic beta cell development, with potential underlying mechanisms including their interaction with the transcription factors that control proliferation and differentiation of the Langerhans islets cells (Gesina et al., 2006). Among these, IGF (insulin-like growth factor) 2, the IGF receptor, and several IGF binding proteins (Hill et al., 2000) may lead to a decreased insulin secretion, with consequent hyperglycaemia in adult life. Prenatal GC exposure is also associated with alterations in fat distribution and function. Offspring of rats treated with dexamethasone during days 8,10 and 12 of pregnancy have increased intra-abdominal fat depots, and a parallel increase in circulating leptin levels (Dahlgren et al., 2001). Moreover, treatment of rats with dexamethasone in the last week of pregnancy leads to an increase in GR expression in visceral adipose tissue and alterations in fat metabolism which may contribute to insulin resistance (Cleasby et al., 2003). Recent evidence also shows that the activity of 11 $\beta$ HSD type 1 may be 'programmed' by prenatal GC therapy. Indeed, a brief antenatal exposure to GCs in pregnant marmosets resulted in up-regulation of 11 $\beta$-HSD1 mRNA expression and activity in subcutaneous, but not visceral, fat of the offspring (Nyirenda et al., 2009). The increase in $11 \beta$-HSD1 occurred before the animals developed obesity or overt features of the metabolic syndrome. This up-regulation of $11 \beta-H S D 1$ suggests a novel mechanism underlying the foetal origins of obesity.

\subsection{The impact of GCs on foetal bone}

Another interesting field of research is represented by the influence of prenatal GCs on foetal bone. Indeed, GCs are known to affect skeletal growth and adult bone metabolism, but their impact on foetal bone remains to be elucidated. Some Authors (Swolin-Eide et al., 
2002) reported prenatal dexamethasone exposure to affect skeletal growth in rats. Dexamethasone-exposed male but not female rat offspring showed transient increases in crown-rump length and tibia and femur lengths at 3-6 weeks of age. In contrast, the cortical bone dimensions were altered in 12-week-old female but not male, and the areal bone mineral densities of the long bones and the spine were unchanged in both male and female suggesting a gender specific effect. Following these results, research was addressed to investigate some biochemical markers of bone turnover such as 4,5 carboxy-terminal propeptide of type I procollagen (PICP) and cross-linked carboxy-terminal telopeptide of type I collagen (ICTP). A single course of antenatal corticosteroids reduced umbilical cord levels of PICP without influence on ICTP (Korakaki et al., 2007). Instead, according to other Authors (Fonseca et al., 2009), umbilical cord serum levels of ICTP, the marker for foetal bone resorption, decreased only when the doses were $\geq 4$.

\subsection{Conclusion}

Overall, it appears that, in animals, programming effects of GCs exposure during gestation involve:

- hyperglycaemia throughout a gluconeogenesis enzyme modulation coupled with a decreased growth of pancreatic islets;

- $\quad$ increased deposition of visceral fat related with an increase in circulating levels of leptin and expression of GR in the fat tissue;

- gender-specific manner stimulation of bone growth without influence on mineralization.

However, the results of these experimental studies, performed on a variety of animal species, using high doses and different types of GC, cannot be extended to human pregnancy, that is provided with distinct metabolising capacity at the utero-placental level. Indeed, GCs are largely prescribed for a variety of maternal and foetal conditions during human pregnancy, where none of the above reported complications and side effects have been confirmed. The absolute indications for using these compounds are Addison syndrome and hypopituarism. Furthermore, they are largely utilized for maternal asthma, collagen disease, ulcerative colitis, regional enteritis, and need of immunosuppression. Moreover, there is a number of specific indications to early administration for pregnancy-induced pathology. Among these foetal atrio-ventricular block, congenital adrenal hyperplasia, cystic adenomatoid malformation of the lung, alloimune thrombocytopenia, recurrent pregnancy loss and antiphospholipid antibody syndrome. In addition, clinical conditions that benefit from use of GCs in advanced pregnancy are related with premature delivery, aimed at the prevention of neonatal respiratory distress syndrome, intraventricular haemorrhage and necrotizing enterocolitis (Lunghi et al., 2010). All above conditions provide evidence for substantial advantages in foetal and maternal prognosis of prenatal administration of GCs, compared to feared, but unproved, side effects such as malformation and intrauterine growth restriction. At this regard, it has been reported that triamcinolone acetonide, a 
synthetic glucocorticoid, induces cleft palate resulting from poor development of palatal shelves in mice (Furukawa et al., 2004). Nevertheless, direct extrapolation to humans of teratogenic effects of GCs in animals is tenuous. Indeed, a prospective controlled cohort study, based on self-reported drug exposure and maternal interview as a source, collected 311 pregnancies receiving systemic use of different GCs in the first trimester. The rate of major congenital anomalies was compared to that of 790 controls that were counselled for non-teratogenic exposure. There was no case of oral cleft and no pattern of anomalies among the GCs exposed group, supporting the opinion that these hormones do not represent a major teratogenic risk in humans (Gur et al.,2004). A survey of the literature concerning 468 pregnant women treated with corticosteroids outside the transplant setting demonstrated an overall malformation rate of $3.5 \%$, thus within the expected incidence in the general population (Danesi \& Del Tacca, 2004). Moreover, a study on more than 6600 infants reported that maternal exposure to orally inhaled budesonide during pregnancy is not associated with an increased risk of congenital malformations or other adverse foetal outcomes (Rahimi et al., 2006). As for foetal growth, a systematic review of animal studies examining the association of GCs on birth outcome reported a reduction in birth weight (Aghajafari, 2002). However, it should be considered that animal experiments demonstrating negative effects employed doses equivalent to 20-100 times a 'replacement' dose of steroids for a human patient. Nevertheless studies in human were addressed to assess both the effect of early exposure protracted for a long time and that of late administration for preventing the complications of premature delivery. Interestingly, although a recent study suggests that foetal growth becomes sensitive to GCs when the treatment starts early and is prolonged for a long time (Gur et al., 2004), dexamethasone given from the $10^{\text {th }}$ week throughout pregnancy in the presence of female foetuses affected by 21-hydroxylase deficiency did not influence weight, length and head circumference of the newborns (Carlson et al., 1999). As for advanced pregnancy, randomized controlled studies have shown that treatment for preventing respiratory distress syndrome of the neonate leads to birth weight reduction only after four or more courses, and that these parameters normalized by the time of hospital discharge (Bonanno et al., 2007). Moreover, a meta-analysis of five trials in which 2028 pregnant women were treated with GCs in late pregnancy found no significant effect on birth weight (Crowther et al., 2007). Two main exceptions can be raised towards human clinical studies: first, the time elapsing between administration of the drug and delivery appears to be too short to influence foetal growth; second, obstetrical diseases affecting foetal growth are necessarily included in the study sample, and therefore it is not possible to discriminate their influence from that of the hormone. The only way to avoid such a bias should be to administrate GC to healthy volunteers along the course of physiological pregnancy, something that happened to us in some way to do, in our long experience with low dose betamethasone therapy throughout gestation (see ahead). Based on our results, there is no persuasive evidence for any adverse effect neither of long duration low dose (see ahead), nor of short duration high dose GC on foetal growth. 


\section{Need and rules for antibiotic and glucocorticoid therapy in advanced pregnancy: The foetal inflammatory response syndrome.}

We have previously treated in a more detailed manner the main indications to glucocorticoid therapy in human pregnancy (Lunghi et al., 2010). Nevertheless, for the purposes of the present chapter, it is necessary to stress the concepts dealing with the "Foetal Inflammatory Response Syndrome" (FIRS) (Romero et al., 1998). Indeed, being paradigmatic of the negative effects of inflammation on pregnancy, it offers the chance to clarify the rationale for the appropriate use of GCs and antibiotics for preventing harmful complications. FIRS is defined as a systemic inflammation characterized by an elevation of foetal plasma IL-6. In this syndrome a foetal plasma IL-6 level above $11 \mathrm{pg} / \mathrm{ml}$ is a major independent risk factor for the subsequent development of severe neonatal morbidity. Such a condition can be found even in the absence of microbial invasion of the amniotic cavity and any other sign of infection, as a foetal immune reaction characterized by increase in monocyte and neutrophil activation, and without correlation with maternal plasma or amniotic fluid concentration of the cytokine. It has been suggested that the foetus uses the effector limb of the immune response via the secretion of pro-inflammatory cytokines to signal the onset of labour and exit a hostile intrauterine environment (Romero et al., 1998). Whatever its teleological meaning, FIRS, also expressed by increased concentrations of foetal MMP-9, an enzyme involved in the digestion of type IV collagen and in the pathophysiology of preterm premature rupture of the membranes, can progress towards multiple organ dysfunction. (Romero et al., 2002). A further enzyme involved in such inflammatory process is MMP-8. Indeed an elevated MMP-8 concentration ( $>23 \mathrm{ng} / \mathrm{mL})$, is present in $81 \%$ of the cases with cervical insufficiency, while a positive microbial culture is found only in $8 \%$. These results indicate that, regardless of the eventual microbial involvement, inflammation is a risk factor for impending preterm delivery (Lee et al., 2008). Overall, the evidences above speak in favour of a leading role of inflammation in the pathogenesis not only of premature birth, but also of ominous perinatal complications such as respiratory distress syndrome (RDS), cerebral haemorrhage and necrotizing enterocolitis (NEC). Evidently, in this perspective, the causal role of infection appears substantially scaled. Accordingly, there is no evidence for a clear benefit of antibiotic treatment in infectious conditions that are associated with premature delivery, such as bacterial vaginosis and urinary infections (McDonald et al., 2007). In addition, treating women at risk with antibiotics does not reduce the incidence of subsequent of preterm delivery (Simcox et al., 2007), and among women with Group B streptococcal bacteriuria, exposure to additional antibiotics even increases the risk (Anderson et al., 2008). Conflicting reports do not clarify the role of prophylactic antibiotic therapy for inhibiting preterm labour. For instance, one meta-analysis including 11 trials on 7428 women with intact membranes showed a reduction in maternal infection, but failed to demonstrate benefit or harm for the neonatal outcome (King et al., 2002). On the contrary routine antibiotic prophylaxis during the second or third trimester of pregnancy reduces the risk of pre-labour rupture of the membranes, with beneficial effects on birth weight and the risk of postpartum endometritis in high risk women, according to a further meta-analysis (Thinkhamrop et al., 2002). As regards to the 
conflicting results of clinical studies about the administration of antibiotics in the prevention and cure of preterm delivery, it must be said that their Authors did not take into account the direct anti-inflammatory capacity that some of them are able to exert on gestational tissues. Indeed, we have demonstrated that ampicillin inhibits PGE release from amnion tissue in vitro, either in basal condition or upon addition of arachidonic acid or oxytocin to the medium (Vesce et al., 1998). Furthermore, it strongly reduces IL-6 level in amniotic fluid of patients sampled 4 hours after drug administration (Vesce et al., 2004). Ceftriaxone and gentamycin significantly and reversibly inhibit both basal and arachidonic acid- or oxytocinstimulated PGE release from amnion, although to a lesser extent compared with ampicillin. On the contrary tetracycline and erythromycin do not influence the PG output. Of key importance from a clinical standpoint, the inhibitory effect of ampicillin is enhanced in an additive manner by ceftriaxone, reduced by gentamycin, and abolished by tetracycline and erythromycin (Vesce F et al., 1999). The above evidences indicate that, at least in pregnancy, the inhibitory action of $\beta$-lactamines on amniotic IL- 6 and PGE release could be of value independently from their antibacterial action. Conversely, the classes of antibiotics that do not exert any inhibition on PGE release should not be used when preterm labour is not induced through a bacterial mediation. Furthermore, in cases of premature labour of inflammatory origin subsequently complicated by superimposed infection, macrolides addition to $\beta$-lactamines may eradicate infection, but it does not counteract the triggering pathogenic mechanism. In other words, in interpreting the efficacy of antibiotics in the management of premature labour, it is mandatory to know whether or not they directly inhibit inflammatory cytokines and prostanoids. It has been claimed that antibiotic therapy of premature labour in the presence of infection leads to the release of microbial products which may exacerbate the cytokine response and worsen the clinical picture. It has been also hypothesized that a similar scenario may occur in patients with microbial invasion of decidua and amniotic cavity. Such an initial worsening of the inflammatory response may accelerate the process of premature parturition and foetal damage. Nevertheless, it has been also suggested that transient down-regulation of the effects of the inflammatory response would permit the time that is required to eradicate the infectious process, without injury to the foetus. Indeed, anti-inflammatory cytokines, antibody to macrophage migration inhibitory factor and antioxidants, may also play a role in preventing delivery, neonatal injury, and long-term perinatal morbidity. Accordingly, a combination of antibiotics and immunomodulators (dexamethasone and indomethacin), in experimental premature labour induced by intra-amniotic inoculation with group B streptococci. in non human pregnant primates, was effective to eradicate infection, suppress the inflammatory response, and prolong gestation (Tsuzuki et al., 2009). One more aspect needs to be clarified before reporting our experience with use of low dose betamethasone for the prevention of pregnancy loss, and it deals with the necessity to discriminate the pathogenic role of prematurity from inflammation and hypoxia. Indeed, prematurity is still reported everywhere as the leading cause of perinatal morbidity and mortality (Mwaniki et al., 2012). Such a concept is obviously provided with some validity, but in the general contest of pregnancy complications it needs to be adequately scaled. Basically, it appears to stem from the link between prematurity and hyaline membrane disease (HMD) of the lung, an 
ominous disease that is ascribed to the failure of immature type II alveolar cells to produce sufficient surfactant (i. e. lecithin). As betamethasone was historically recognized to be able to prevent HMD, its efficacy was intended as a sort of "maturational promotion". However, there are good reasons to believe that the main pathogenic mechanism is rather of a hypoxic-inflammatory type. Indeed, premature foetuses express RDS of diverse intensity at the same gestational age, in relation with the grade of the pathology causing premature birth. Pregnancy complications leading to premature birth are largely a consequence of an inflammatory mechanism. Accordingly, prematurity is characterized by two other complications, i. e. NEC and encephalopathy, marked by high levels of inflammatory cytokines that also benefit from the action of betamethasone. Finally, the drug efficacy is limited to its timely prenatal administration, as it lacks when the hormone is given after birth, suggesting that it stimulates the production of an extra amount surfactant at a level other than the foetal alveoli that is subsequently delivered to the lung before birth thru gasping efforts a typical feature of foetal hypoxia. As we have demonstrated, the site of lecithin release in the foetal compartment is represented by amnion tissue (Vesce F et al., 1992). Based on these considerations, chronic intrauterine distress appears to play a major role compared to gestational age in the pathogenic mechanism of the 'prematurity' syndrome. Indeed, all above evidences indicates that FIRS proceeds from inflammatory processes endowed themselves with the capacity to lead to all above mentioned dangerous perinatal complications, infection included. Timely addition of GCs addressed to rebalance cytokines and prostanoids regulating the inflammatory response, represents therefore an unavoidable therapeutic approach.

\section{Personal experience with low-dose betamethasone administration throughout pregnancy for prevention of pregnancy loss}

The clinical observations by the corresponding author of the present chapter regarding pregnancy loss begun during the early seventies, when progesterone therapy was the main choice in cases of either threatened or recurrent abortion at the Department of Obstetrics and Gynaecology of Ferrara University. However, as ultrasounds became available, it clearly appeared to the echographers that, based on the above mentioned theoretical benefits, the drug was given blindly, even to patient with missed abortion as well as to those who never would have needed it. Indeed, there was no practical way (as it still substantially lacks today) to investigate the causes of abortion in single cases, and the explanation given to the patient dealt almost invariably with either corpus luteum deficiency or aneuploidy. Soon after we were informed that corticosteroids had been occasionally used successfully in patients with recurrent abortion when an "immunological basis" for rejection of the conceptus was hypothesized (Professor Denis Hawkins, of London, personal communication). In addition, administration of cortisone $25-75 \mathrm{mg} /$ day up to 64 days during the first trimester for the treatment of hyperemesis had already been reported long before (Wells, 1953). At that stage, after observing many more cases of recurrent abortion, all treated with various regimens of progesterone, we concluded that there was no reason for further giving this drug to such women. The first case of recurrent abortion occasionally 
treated with betamethasone was 34 years ago a patient with bronchial asthma that, in spite of progesterone therapy, had experienced three early pregnancy losses. Subsequently she had gone through two years of anovulatory sterility, followed by several attempts to medical induction of ovulation, all ended in ovarian hyperstimulation syndrome. This patient was therefore counselled to assume $0.5 \mathrm{mg}$ betamethasone daily for the next three months for treating asthma, and she started a spontaneous pregnancy one month later. Once adequately informed of a possible protective action of the hormone, she accepted to continue with the same regimen up to the end of pregnancy, when she delivered a normal foetus. Such a successful outcome encouraged us to cautiously adopt over the years low dose betamethasone therapy in all our patients with history of recurrent abortion previously unsuccessfully treated with progesterone. Furthermore, as we became aware of the high efficacy of the hormone, we extended its use to some other cases where protection of the first pregnancy was advisable even in the absence of previous pregnancy loss. These included, for instance, women of advanced age with or without previous sterility. We may say that there are several reasons for such a policy. The first one is represented by the lack of efficacy of progesterone in our experience, coupled with the tenuous and controversial evidence of a protective role in the above reported literature. A further point in favour of preventive GCs administration is that there are women who will not have the chance of a second pregnancy, and therefore they are suitable for prevention of possible inflammatory complications, for the timely diagnosis of which there are no available tests in the clinical practice. Indeed, as it became clear later on, GCs regulate the inflammatory process by modulating cytokine production (IL-6 and TNF $\alpha$ ) (Thum et al., 2008) and decreasing maternal NK population (Quenby et al., 2005), two among the good reasons to adopt them in the clinical management of these cases. The study of this particular mechanism of GC in early pregnancy has been enhanced in the last years the focus being directed on prednisolone, the role of which in the prevention of recurrent pregnancy loss is currently under trial (Thang et al., 2009). However, its pharmacokinetic characteristics require a high dose to obtain the therapeutic effect. For instance, in the case reported by Quenby et al. (2003), a patient with history of 14 consecutive abortions between the 8th and 10th week of gestation, first received $5 \mathrm{mg}$ /day preconceptual prednisolone, leading to 5 further abortions. Only when the dose was raised up to $20 \mathrm{mg} /$ day she became able to deliver a preterm viable baby. Indeed, as it has been explained above, the trans-placental passage of the drug is highly impaired by $11-\beta-$ HSD isoenzymes. By contrast, compared to prednisolone, betamethasone is little metabolized by the placenta and it is ten times more effective (Burton \& Waddell, 1999). Therefore, we decided to focus on betamethasone that is extensively used in advanced pregnancy for prevention of neonatal respiratory distress syndrome (Sotiriadis et al., 2009) but it is not adopted in early pregnancy, due to all above mentioned possible negative influences in animals, although they have not been confirmed in humans. Taking into account all these evidences, we choose to administer a low dose betamethasone, in order to obtain a better protective effect on pregnancy, avoiding at the same time significant maternal dose-dependent side effects. In our experience this therapeutic approach proved to be coupled with great efficacy and lack of significant complications. We treated over 200 cases until today, as other pregnancies are going on at the moment, the main indication being a history of recurrent pregnancy loss. There were cases in 
which the usual dose of $0.5 \mathrm{mg} /$ day was ineffective to prevent abortion, and it was doubled during the subsequent pregnancy, to be increased up to $2 \mathrm{mg} /$ day month by month, due to heavy bleeding around the time of the expected menstrual flow. These cases, not included in the sample below, ultimately ended with the birth of healthy babies around term. As expected, there were cases of pregnancy complications, such as premature delivery, IUGR, preeclampsia, abruptio placentae, gestational diabetes, that were handled with the standard obstetric care. Indeed, betamethasone does not represent the panacea for every adverse gestational condition. Overall, besides the high effectiveness of the therapy in preventing pregnancy loss, we can testify that neither foetal malformations nor significant maternal or foetal adverse effect of betamethasone were observed. No chance of a prospective randomized case-control study was offered at our Institution, in order to statistically prove the greater efficacy of betamethasone compared to other therapies. However we were able to analyze retrospectively a total of 101 treated patients as regards to some foetal biometric parameters and birth weight. Furthermore we performed two prospective studies aimed at verify two relevant end-points provided with physio-pathologic and clinical implications:

- the possible positive correlation of foetal growth restriction with maternal peripheral NK cells concentration;

- the possible efficacy of low-dose betamethasone therapy in decreasing the maternal peripheral NK cells concentration.

Our retrospective analysis includes 166 patients admitted to the Section of Obstetrics and Gynaecology of Ferrara University from the late seventies to 2010. The population was divided into three groups:

- (Group A): 80 patients treated by low dose betamethasone $(0,5 \mathrm{mg} / \mathrm{daily})$ throughout pregnancy for previous history of recurrent miscarriage;

- (Group B): 65 patients with physiological pregnancy;

- (Group C): 21 patients affected by rheumatologic disease treated by prednisone (4-16 $\mathrm{mg} /$ daily).

Foetal growth was assessed by measuring the weight, head circumference and length at the birth. First data evaluation revealed neonatal weight and length significantly lower in the treated groups $(2843,5 \mathrm{~g}$ and $48,14 \mathrm{~cm}$ in group A; 3262,92 $\mathrm{g}$ and $49,93 \mathrm{~cm}$ in group B; $2901,90 \mathrm{~g}$ and 49,67 in group C (Figure 2). Instead the head circumference was not statistically different among three groups (respectively $33.6 \mathrm{~cm}, 34.03 \mathrm{~cm}$ and $34.3 \mathrm{~cm}$ ).

However in evaluating biometric parameters of the newborns, the pathological conditions of pregnancy that may lead to foetal growth restriction must be considered (Grivell et al., 2009). Among these, premature delivery, pre-eclampsia, gestational diabetes, hypothyroidism and bronchial asthma (Murphy \& Gibson, 2011; Mitanchez, 2010; Krassas et al., 2010). Therefore, to get a more accurate evidence of the effect of betamethasone alone on foetal growth, we normalized the study population by excluding 26 patients suffering from the above mentioned diseases. By doing so, as expected, the differences among the neonatal biometric parameters were no more significant in the three groups (3144 g, $3262 \mathrm{~g}$ and 3171 
g respectively for the birth weight; $49.73 \mathrm{~cm}, 49.3 \mathrm{~cm}$ and $49.63 \mathrm{~cm}$ for the neonatal length; $34.25 \mathrm{~cm}, 34.03 \mathrm{~cm}$ and $34.53 \mathrm{~cm}$ for the head circumference) (Figure 3).

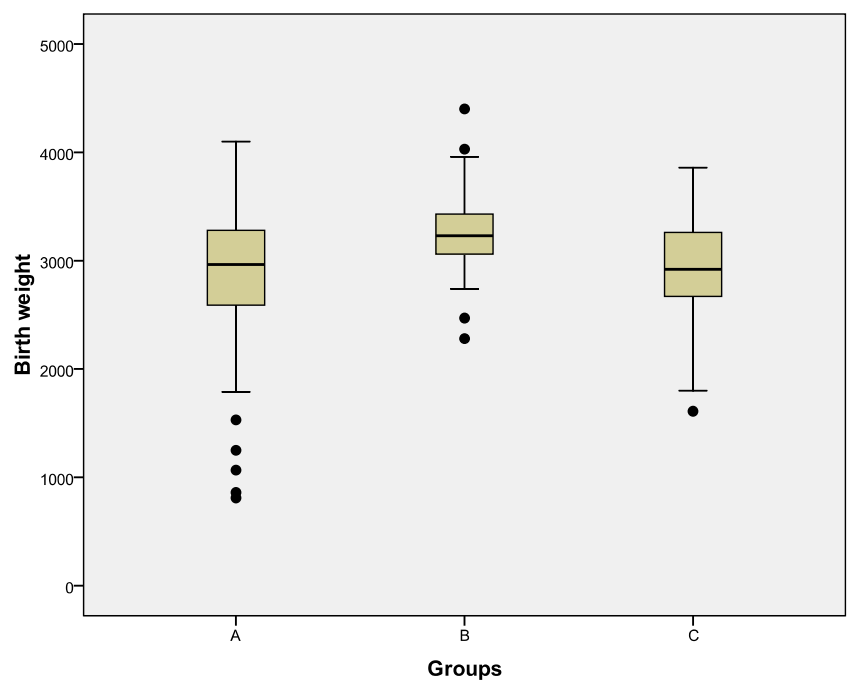

Figure 2. Distribution of birth weight in three groups. Group A (treated by betamethasone): $2843,5 \mathrm{~g}$; Group B (physiologic pregnancy): 3262,92 g; Group C (rheumatologic diseases): 2901,90 g.

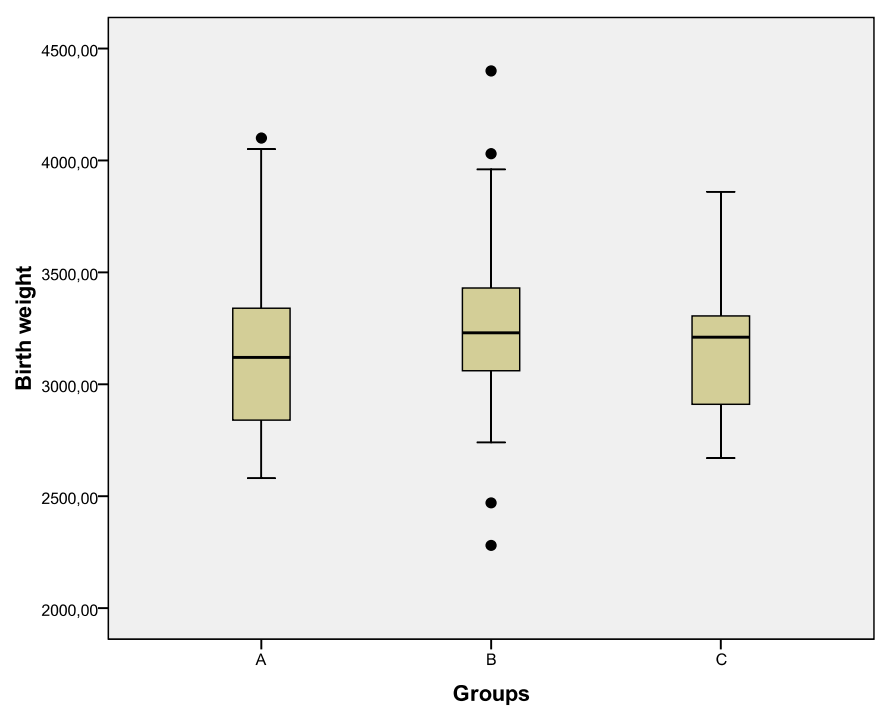

Figure 3. Distribution of birth weight in three groups after normalization of the study population. Group A (treated by betamethasone): 3144 g; Group B (physiologic pregnancy) 3262 g; Group C (rheumatologic diseases): $3171 \mathrm{~g}$. 
Moreover, by analyzing the distribution of birth weight values, we observed that one third of the newborns reached a weight higher than the fiftieth percentile in the treated group. Being all the patients upon the same betamethasone regimen, such an observation confirms that the cause of decreased neonatal weight should be ascribed to factors other than the hormone. The result of our attempt to homogenize the study sample highlights the need to take with caution the conclusions of other reports where different classes of patients were accidentally mixed up. As a matter of fact, most cases of GCs administration reported in the literature belong to pathologic conditions leading by themselves to foetal growth restriction (Davis et al., 2009; Kumar \& Seshadri, et al., 2005). Coming to our first prospective study, we must recall that impairment of foetal oxygenation and growth, besides being linked with the above mentioned influences of unbalanced cytokines on utero-placental perfusion, is also reflected in the correlation between high values of uNK and IUGR (Williams et al., 2009). Therefore we decided to analyze the circulating lymphocyte subsets, mainly to search for a correlation between peripheral maternal NK concentration and foetal growth restriction. Such a possible link, to our knowledge never investigated before, could open the way to a practical test for the early diagnosis of a harmful complication. We selected ten pregnant women with a history of a successful pregnancy as a control group (group 1), plus ten with a diagnosis of IUGR, i.e. with foetal ultrasound biometric parameters below the 10th percentile (group 2). The course of pregnancy was normal in both groups, ending in spontaneous or elective caesarean delivery at term. Fresh blood samples drawn during the third trimester were analyzed at the Laboratory of the Haematological Unit of Ferrara University. Our study demonstrates that the number of peripheral leukocytes, the number of lymphocytes and their percentage were constant $(p<0,75 ; p<0,93 ; p<0,49)$ while significant changes are observed for the NK cells. In particular:

- $\quad$ Significantly higher NK percentage $(\%$ CD56 cells) in group $2(20,9)$ compared to group $1(15,1)(\mathrm{p}<0,01)$ (Figure 4);

- No significant increase in NK total number $\left(\mathrm{CD}^{2} 6^{+} \mathrm{U} / \mu \mathrm{l}\right.$ cells) $(419,6)$ in group 2 compared to group $1(341,4)(\mathrm{p}<0,10)$;

- Significantly higher percentage $\mathrm{NK}$ subset $\left(\mathrm{CD} 2{ }^{+} \mathrm{CD} 56^{+}\right.$cells) in group $2(18,8)$ compared to group $1(13,4)(\mathrm{p}<0.02)$ (Figure 5).

By analyzing the other lymphocyte subsets, we observed a non significant $\mathrm{CD} 4{ }^{+} \mathrm{T}$ decrease along with a $\mathrm{CD} 8{ }^{+} \mathrm{T}$ increase, with a consequent decrease of their ratio. Moreover, there were no differences in the absolute count and percentage of the following lymphocyte subsets: $\mathrm{T}\left(\mathrm{CD}^{+}\right)$lymphocytes, $\mathrm{T}$ activated lymphocytes (CD3 ${ }^{+}$HLA-DR $\left.{ }^{+}\right), \mathrm{CD} 45$ leukocytes, HLA-DR cells and B lymphocytes (CD19+ e CD19+CD5+).

Therefore, increased peripheral NK percentage was the only significant feature of lymphocyte subset linked with IUGR in our study sample. Subsequently, with the aim to contribute to a better knowledge of the basic mechanisms of GCs protection, we evaluated the influence of betamethasone on the percentage of maternal $\mathrm{pNK}$ and other components of the lymphocyte subset in women with history of RSA. The patients with known anatomical, hormonal, genetic, infectious, autoimmune causes of abortion, as well as those with psychiatric disease were excluded from the study. Ten pregnant women with history of RSA 


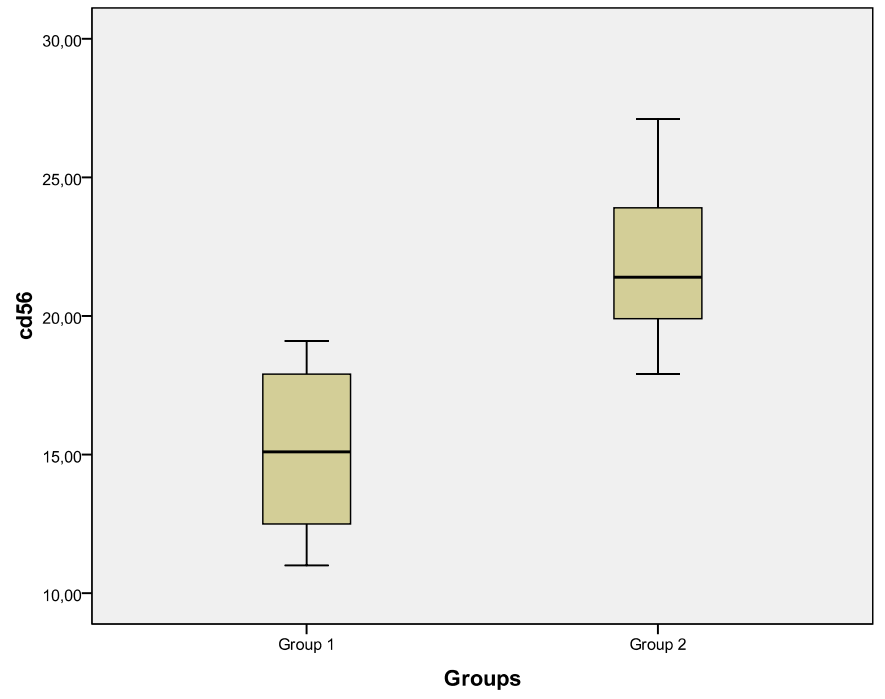

Figure 4. Comparison of pNK percentage $(\% \mathrm{CD} 56+)$ between patients with adequate foetal growth (Group 1) and those with growth restriction (Group 2)

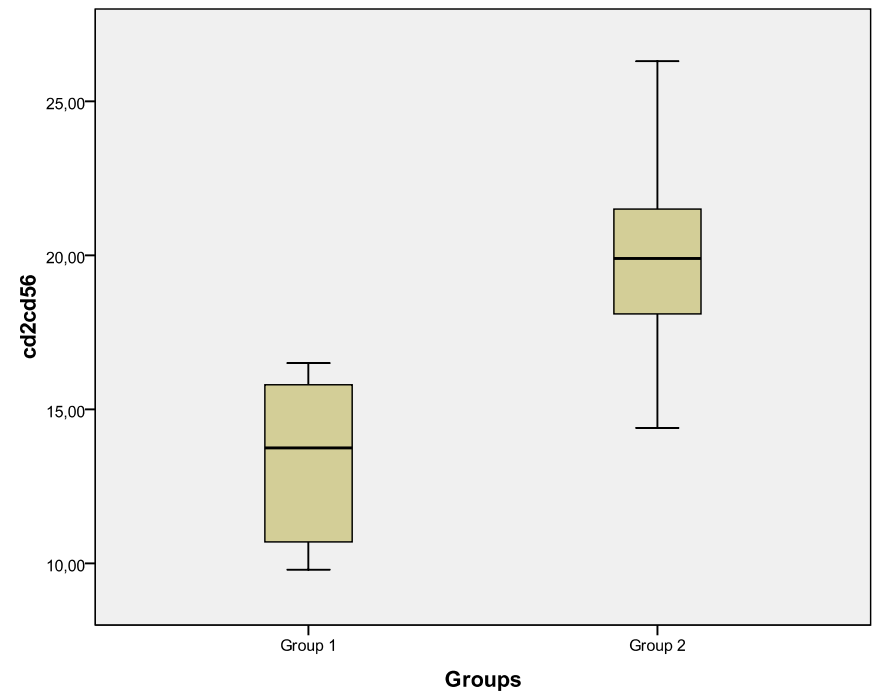

Figure 5. Comparison of the mean value of the CD2 + CD56 + subset percentage between patients with adequate foetal growth (Group 1) and those with growth restriction (Group 2). 
were consecutively recruited (group 1). They were given oral betamethasone $0.5 \mathrm{mg} /$ daily from the fifth week of pregnancy until delivery. Ten normal pregnant women with previous history of successful pregnancies served as a control group (group 2). Blood samples were drawn at each one of the three trimesters (t1-first trimester, t2-second, t3-third). Fresh samples were analyzed at the Laboratory of the Haematology Unit of Ferrara University. The comparison between the two groups showed that lymphocytes percentage was significantly lower upon betamethasone therapy only in the third trimester ( $\mathrm{p}$-value $=0,035$ ). The percentage of T CD4+ cells in the third trimester was higher in treated women $(46,4 \%)$ compared with controls $(42,2 \%)$ ( $\mathrm{p}$-value $=0,031)$, while that of T CD8+ cells was significantly lower in RSA in the second and in the third trimester. Comparison of CD2+, CD3+, CD5+, CD19+, CD45+, CD3+HLA-DR+ and CD19+CD5+ cells percentage between groups revealed no difference. As for NK, during the first trimester their percentage in RSA did not differ from that of the controls ( $\mathrm{gr} 1=15,0 \%, \mathrm{gr} 2=15,3 \%$ ). However in the second trimester it became significantly lower (gr1 $=15,2 \%$, gr $2=17,6 \%$, p-value $=0,045$ ). In the third trimester, despite a drop of their percentage (reaching 12,0\%), only the absolute NK count decrease reached statistical significance. The percentage of NK subset CD2+CD56+ in the second and third trimester was significantly lower in group 1 (Figure 6). Our data on controls show the absence of significant changes in leukocyte and NK count and percentage throughout pregnancy. Coming to leukocyte subsets, we registered a lymphocytes decrease in the second trimester and a subsequent raise in the third, and a T CD4+ lymphocytes decrease with a T CD8+ increase throughout pregnancy. All together, these results substantially agree with the previous studies on physiologic pregnancy (Radysh et al., 2005).

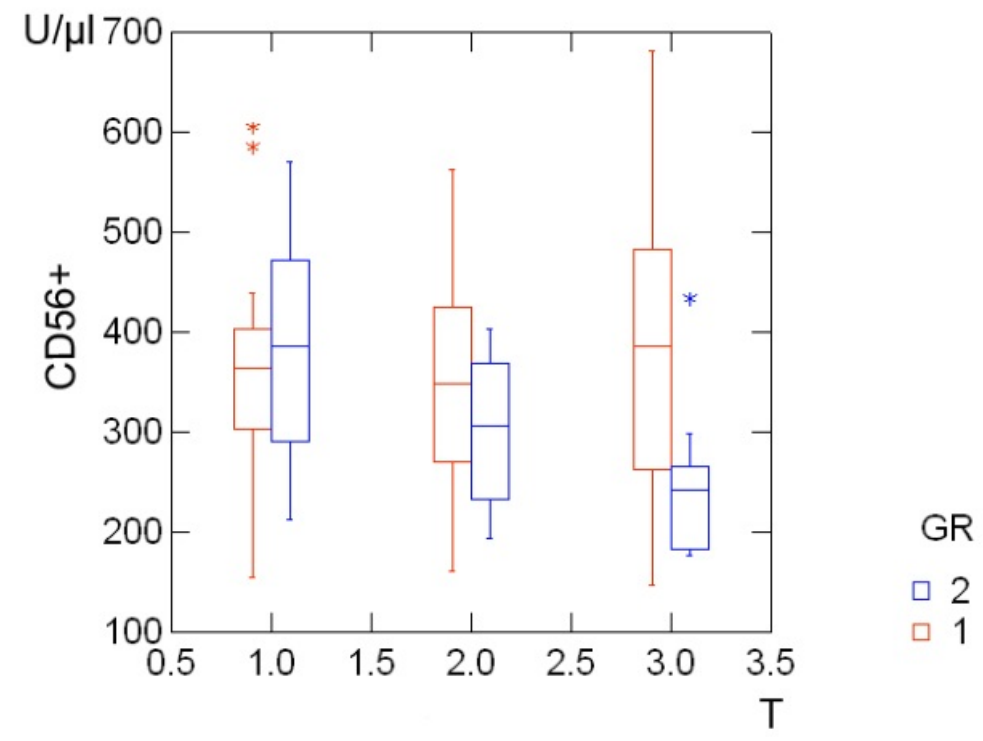

Figure 6. Trend of CD56 + cells $\mathrm{U} / 1$ in group 1 and group 2 in the three trimesters. Time $=1.01^{\wedge}$ trimester, $2.0=2^{\wedge}$ trimester, $3.0=3^{\wedge}$ trimester. $\mathrm{Gr} 1=$ normal pregnancy, $\mathrm{Gr} .2=$ pregnancy with history of RSA treated with betamethasone 
In the present study, moreover, we found that chronic low dose betamethasone administration leads to a significant decrease of leukocyte total number. Such behaviour is opposite to the well known leukocyte increase that follows $24 \mathrm{mg}$ betamethasone administration during the third trimester for the prevention of hyaline membrane disease of the newborn. In addition, the lymphocytes percentage decrease caused by betamethasone reached statistical significance compared with controls in the third trimester. Such a result is likely to be related to the reduction of $\mathrm{pNK}$. In treated cases NK percentage and number during the second and third trimester respectively reached lower values compared to controls. However, their values during the first trimester did not differ. Since it has been reported that women with history of RSA have a higher peripheral NK percentage, the absence of a difference between treated cases and physiological pregnancies during the first trimester in our data can be interpreted as an effect of betamethasone administration. In other words, betamethasone in RSA was able to decrease NK to values equal to (first trimester) and lower than (second and third) those in physiological pregnancy. With regard to the other lymphocyte subsets, it had been reported that women with RSA have a higher T cytotoxic CD8+ and $\mathrm{T}$ activated cells (CD3+HLA-DR+) percentage as compared to physiological pregnancy. Our work showed that betamethasone is able to decrease T CD8+ percentage to the same or even lower values compared to physiological pregnancy. In addition, we found no differences for $\mathrm{T}$ activated cells, between physiological pregnancy and treated RSA group, probably due to a suppressive action of the hormone. Previous studies demonstrated a CD19+CD5+ decrease in normal pregnancy. These are B lymphocytes producing auto-antibodies, and their percentage typically raises in RSA and in ANA positive women. Indeed, their percentage is reported to fall from $4,17 \%$ in the first trimester to $1,92 \%$ in the third. In contrast, we did not find any difference in CD19+CD5+ percentage between the 2 groups. In conclusion, our research shows that $0.5 \mathrm{mg} / \mathrm{day}$ betamethasone therapy throughout pregnancy in RSA women reduces pNK cells, CD19+CD5+ and CD3+HLA-DR+ lymphocytes. Such a finding, based on the above reported data in the literature, suggests that, besides the possible rebalancing effect of the drug upon the inflammatory cytokines at the implantation site, successful outcome probably derives also from an action on the cellular components of the immune system. It is noteworthy that the clinical result is obtained with use of a low dose that proved to be harmless for the foetus and devoid of maternal side effects.

\section{Conclusive remarks}

We have reported in the present chapter the regulation of the gestational processes as it appears from the data in the literature. Pregnancy can be essentially interpreted as a vascular phenomenon resulting from a balanced activation and release of a great number of mediators upon hormonal control. Corpus luteum progesterone is required before conception in order to adapt the uterine decidua to the subsequent early phase of implantation. However it was shown long ago that from the seventh week onward the corpus luteum is no more needed, as at this stage castration becomes unable to interrupt pregnancy. In spite of such evidence, the hormone is extensively used for prevention of 
abortion, and it keeps on being advocated even later on (Lucovnik et al., 2011), mainly based on its immuno-modulatory and myometrial relaxing effects. Recent research shed light on a more relevant cause of pregnancy loss than progesterone deficiency that is represented by inflammation at any stage of the gestational process. It can be triggered along a number of pathways, infection included. Nevertheless, infection, although accounting for ominous complications, has been found in some cases to represent a consequence rather than the cause of gestational inflammation. Inflammatory changes appear quite often to derive from a derangement of cytokines and prostanoids involved in the regulation of gestational physiological processes. A great number of cell function mediators has been found to be linked either with favourable outcome or with pregnancy loss, depending on the experimental model as well as on the gestational stage, but none can be identified alone as the keystone, successful pregnancy appearing the result of a balanced action of all mediators together. On the contrary, their imbalance leads to the activation of blood coagulation and stimulation of uterine contraction, the basic mechanisms for any pregnancy loss, aneuploid included (Vesce et al., 1996; Vesce et al., 2001; Vesce 2002). Myometrial activity is triggered by the release of prostanoids, mainly PGs of the E type, upon the action of many unbalanced cytokines. During the first trimester such abnormalities are confined to the feto-placental unit, while from late second to the third they can involve the maternal organism as well, leading to the variable clinical signs of preeclampsia. Outcome of pregnancy depends on the time of onset, the grade and the duration of cytokine imbalance. Moreover it must be considered that the maternal vascular adaptation is induced by the foetus itself, through the action of mediators released by trophoblastic cells on the uterine spiral arteries, and that even apparently late complications, such as preeclampsia, derive their origin from early foetal inadequacy (Vesce et al., 1997) Derangement of such mediators largely recognizing an inflammatory pathogenic mechanism, and low dose betamethasone being devoid of significant foetal side effects, there is no reason for administrating the glucocorticoids whose transfer to the foetus is highly impaired by $11 \beta-\mathrm{HSD}$ iso-enzymes. Indeed two possible scenarios can be identified:

- the trophoblast is able to modify the uterine vessels, but the unfavourable decidual environment impairs such a potential capacity;

- the maternal environment is favourable, but the trophoblast is unable to correctly operate.

In either one of the cases, there are several possible treatments that, like in any other disease, can be classified as symptomatic or etiological: the first are addressed to counteract uterine contractions and blood clotting, the second aimed at rebalancing maternal, as well as foetal, cytokine derangement that leads to abnormal prostanoids release. However, none of the available therapeutic options is able to reverse endothelial damage, once it is already established. Moreover, only etiological therapies are provided with the capacity to prevent the clinical pictures of pregnancy loss in high risk cases. Therefore, once the risk identified, etiological prevention and cure must start as early as possible, in some cases even before conception, and last enough to ensure foetal survival. In our opinion, GCs are the best preventive choice, as they represent the natural controller of the cross-talk that trophoblast 
entertains with maternal cells, throughout their entangled cytokine network. In this perspective, their efficacy is not to be intended simply as the result of a mere antiinflammatory action, but rather as a complex direct and indirect regulatory influence on the mediators of cell functions. For instance, betamethasone, from one hand directly downregulates the synthesis of inflammatory cytokines, while from the other it indirectly does the opposite by stimulating the MIF system. Unfortunately, in spite of the clinical evidence of the lack of significant maternal and foetal side effects of appropriate doses extensively reported in the literature, coupled with the great therapeutic benefits in life-threatening pregnancy complications, the concern for a negative impact on foetal morphogenesis and growth, mainly derived from experiments in animals with use of high doses, still impairs the correct adoption of GCs in the prevention of gestational risk. In the present chapter we reported some data from our long term use of low dose betamethasone throughout gestation for the prevention of pregnancy loss. Basically it is justified by the concept that pregnancy loss is the results of a cytokine imbalance possibly leading to inflammation, a derangement for which the use of progesterone is clinically proved to be either unsuitable or ineffective. In our experience, low dose betamethasone therapy is provided with great efficacy and devoid of significant foetal and maternal side effects. It will keep on representing the first choice therapy for protection of pregnancy in our practice.

\section{Author details}

Fortunato Vesce, Emilio Giugliano, Elisa Cagnazzo,

Stefania Bignardi, Elena Mossuto, Tarcisio Servello and Roberto Marci

Department of Biomedical Sciences and Advanced Therapy,

Section of Obstetrics and Gynecology, University of Ferrara, Italy

\section{References}

Abou-Ghannam G, Usta IM, Nassar AH (2011) Indomethacin in Pregnancy: Applications and Safety Am J Perinatol In press

Aghajafari F (2002) Repeated doses of antenatal corticosteroids in animals: a systematic review. American Journal of Obstetrics and Gynecology 186:843

Al-Bahrani A, Taha S, Shaath H \& Bakhiet M (2007) TNF-alpha and IL-8 in acute stroke and the modulation of these cytokines by antiplatelet agents. Curr Neurovasc Res 4:31-7

Anderson BL, Simhan HN, Simons K \& Wiesenfeld HC (2008) Additional antibiotic use and preterm birth among bacteriuric and nonbacteriuric pregnant women. Int J Gynaecol Obstet 102:141-5

Annells MF, Hart PH, Mullighan CG, Heatley SL, Robinson JS \& McDonald HM (2005) Polymorphisms in immunoregulatory genes and the risk of histologic chorioamnionitis in Caucasoid women: a case control study. BMC Pregnancy Childbirth.5:4

Arck PC, Gilhar A, Bienenstock J \& Paus R (2008) The alchemy of immune privilege explored from a neuroimmunological perspective. Curr Opin Pharmacol 8: 480-9. 
Arcuri, F., Ricci, C., Ietta, F., Cintorino, M., Tripodi, S.A., Cetin, I., Garzia, E., Schatz, F., Klemi, P., Santopietro, R. et al. (2001) Macrophage migration inhibitory factor in the human endometrium: expression and localization during the menstrual cycle and early pregnancy. Biol. Reprod., 64, 1200-1205.

Arcuri F, Cintorino M, Carducci A, Papa S, Riparbelli MG, Mangioni S, Di Blasio AM, Tosi P \& Viganò P (2006) Human decidual natural killer cells as a source and target of macrophage migration inhibitory factor. Reproduction. 131:175-82.

Baglin T, Gray E, Greaves M, Hunt BJ, Keeling D, Machin S, Mackie I, Makris M, Nokes T, Perry D, Tait RC, Walker I \& Watson H (2010) Clinical guidelines for testing for heritable thrombophilia. Br J Haematol 149: 209-220

Bates SM, Greer AI, Pabinger I, Sofaer S \& Hirsh J (2008) Venous thromboembolism, thrombophilia, antithrombotic therapy, and pregnancy: American College of Chest Physicians Evidence- Based Clinical Practice Guidelines (8th edition). Chest. 133: 844S88

Bechi N, Ietta F, Romagnoli R, Jantra S, Cencini M, Galassi G,Serchi T, Corsi I, Focardi S \& Paulesu L (2010) Environmental levels of para-nonylphenol are able to affect cytokine secretion in human placenta. Environ Health Perspect 118: 427-31

Biondi C, Pavan B, Ferretti ME, Corradini FG, Neri LM \& Vesce F (2001) Formyl-methionylleucyl-phenylalanine induces prostaglandin E2 release from human amnion-derived WISH cells by phospholipase C-mediated [Ca+]i rise. Biol Reprod. 64:865-70.

Biondi C, Ferretti ME, Pavan B, Lunghi L, Gravina B, Nicoloso MS, Vesce F \& Baldassarre G (2006) Prostaglandin E2 inhibits proliferation and migration of HTR-8/SVneo cells, a human trophoblast-derived cell line. Placenta 27:592-601.

Bonanno C, Fuchs K \& Wapner RJ (2007) Single versus repeat courses of antenatal steroids to improve neonatal outcomes: risks and benefits. Obstet Gynecol Surv 62:261-71

Bondza PK, Metz CN \& Akoum A (2008) Postgestational effects of macrophage migration inhibitory factor on embryonic implantation in mice. Fertil Steril.90:1433-43

Boomsma CM, Kavelaars A, Eijkemans MJ, Lentjes EG, Fauser BC, Heijnen CJ \& Macklon NS (2009) Endometrial secretion analysis identifies a cytokine profile predictive of pregnancy in IVF. Hum Reprod. 24:1427-35.

Broering R, Montag M, Jiang M, Lu M, Sowa JP, Kleinehr K, Gerken G \& Schlaak JF (2011) Corticosteroids shift the Toll-like receptor response pattern of primary-isolated murine liver cells from an inflammatory to an anti-inflammatory state.Int Immunol 23:537-44

Burrows TD, King A \& Loke YW (1996) Trophoblast migration during human placental implantation. Hum Reprod Update 2:307-21.

Burton PJ \& Waddell BJ (1999) Dual function of 11beta-hydroxysteroid dehydrogenase in placenta: modulating placental glucocorticoid passage and local steroid action. Biol Reprod. 60:234-40

Buzzi M, Vesce F, Ferretti ME, Fabbri E \& Biondi C (1999) Does formyl-methionyl-leucylphenylalanine exert a physiological role in labor in women? Biol Reprod. 60:1211-6.

Calandra T, Bernhagen J, Metz CN, Spiegel LA, Bacher M, Donnelly T, Cerami A \& Bucala R (1995) MIF as a glucocorticoid-induced modulator of cytokine production. Nature 377: 68-71. 
Calandra T \& Roger T (2003) Macrophage migration inhibitory factor: a regulator of innate immunity. Nat Rev Immunol 3: 791-800

Calleja-Agius J, Jauniaux E, Pizzey AR \& Muttukrishna S (2012) Investigation of systemic inflammatory response in first trimester pregnancy failure. Hum Reprod. 27:349-57.

Cardaropoli S, Paulesu L, Romagnoli R, Ietta F, Marzioni D, Castellucci M, Rolfo A, Vasario E, Piccoli E, Todros T. Macrophage migration inhibitory factor in fetoplacental tissues from preeclamptic pregnancies with or without fetal growth restriction. Clin Dev Immunol. 2012;2012:639342.

Carlson AD, Obeid JS, Kanellopoulou N, Wilson RC \& New MI (1999) Congenital adrenal hyperplasia: update on prenatal diagnosis and treatment. J Steroid Biochem Mol Biol. 69:19-29.

Carp HJ (2009) Aspirin in Recurrent Miscarriage: Is There an Indication? Isr Med Assoc J 11:178-82

Cervellati F, Pavan B, Lunghi L, Manni E, Fabbri E, Mascoli C, Biondi C, Patella A \& Vesce F (2011) Betamethasone, progesterone and RU-486 exert similar effects on connexin expression in trophoblast-derived HTR-8/SVneo cells. Reprod Fertil Dev. 23:319-28

Challis JR, Lockwood CJ, Myatt L, Norman JE, Strauss JF 3rd, Petraglia F. Inflammation and pregnancy. Reprod Sci. 16:206-15

Chaouat G, Dubanchet S \& Ledée N (2007) Cytokines: important for implantation? J Assist Reprod Genet 24: 491-505

Cheah FC, Winterbourn CC, Darlow BA, Mocatta TJ \& Vissers MC (2005) Nuclear factor kappaB activation in pulmonary leukocytes from infants with hyaline membrane disease: associations with chorioamnionitis and Ureaplasma urealyticum colonization. Pediatr Res. 57:616-23.

Christiansen OB, Pedersen B, Rosgaard A \& Husth M (2002) A randomized, double-blind, placebo-controlled trial of intravenous immunoglobulin in the prevention of recurrent miscarriage: evidence for a therapeutic effect in women with secondary recurrent miscarriage. Hum Reprod 17:809-816

Clark DA, Chaouat G, Arck PC, Mittruecker HW \& Levy GA (1998) Cytokine-dependent abortion in CBA $\times$ DBA/2 mice is mediated by the procoagulant fgl2 prothrombinase. J Immunol. 160:545-9.

Clark P, Walker ID, Langhorne P,Crichton L, Thomson A, Greaves M, Whyte S \& Greer IA (2010) The Scottish Pregnancy Intervention Study: a multicenter randomized controlled trial of low molecular weight heparin and low dose aspirin in women with recurrent miscarriage. Blood 115:4162-4167

Cleasby ME, Kelly PA, Walker BR \& Seckl JR (2003) Programming of rat muscle and fat metabolism by in utero overexposure to glucocorticoids, Endocrinology 144:999-1007

Comp PC, Thurnau GR, Welsh J \& Esmon CT (1986) Functional and immunologic protein S levels are decreased during pregnancy. Blood 68: 881-5

Coomarasamy A, Truchanowicz EG \& Rai R (2011) Does first trimester progesterone prophylaxis increase the live birth rate in women with unexplained recurrent miscarriages? BMJ. 342:d1914. 
Cox SM,Bohman VR,Sherman ML \& Leveno KJ (1996) Randomized investigation of antimicrobials for the prevention of preterm birth. Am J Obstet Gynecol 174: 296-10

Cowchock S \& Reece EA (1997) Do low-risk pregnant women with antiphospholipid antibodies need to be treated? Organizing Group of the Antiphospholipid Antibody Treatment Trial. Am J Obstet Gynecol 176: 1099-100

Cronier L, Alsat E, Harve` JC, De'le'ze J \& Malassine`A (1998) Dexamethasone stimulates gap-junctional communication, peptide hormone production and differentiation in human term trophoblast. Placenta 19(Suppl. 1), 35-49

Crowther CA \& Harding JE (2007) Repeat doses of prenatal corticosteroids for women at risk of preterm birth for preventing neonatal respiratory disease. Cochrane Database Syst Rev 3:CD003935

Cunha FQ, Weiser WY, David JR, Moss DW, Moncada S \& Liew FY (1993) Recombinant migration inhibitory factor induces nitric oxide synthase in murine macrophages. J Immunol 150: 1908-12.

Dahlgren J, Nilsson C, Jennische E, Ho HP, Eriksson E, Niklasson A, Björntorp P, Albertsson Wikland K \& Holmäng A. (2001) Prenatal cytokine exposure results in obesity and gender-specific programming, Am. J. Physiol. Endocrinol. Metab. 281:E326-E334

Danesi R \& Del Tacca M (2004) Teratogenesis and immunosuppressive treatment. Transplant Proc 36:705-7

Davis EP, Waffarn F, Uy C, Hobel CJ, Glynn LM \& Sandman CA (2009) Effect of prenatal glucocorticoid treatment on size at birth among infants born at term gestation. J Perinatol 29:731-7

de Vries A, Holmes MC, Heijnis A, Seier JV, Heerden J, Louw J, Wolfe-Coote S, Meaney MJ, Levitt NS \& Seckl JR (2007) Prenatal dexamethasone exposure induces changes in nonhuman primate offspring cardiometabolic and hypothalamic-pituitary-adrenal axis function. J. Clin. Invest. 117:1058-1067

Dekel N, Gnainsky Y, Granot I \& Mor G (2010) Inflammation and implantation. Am J Reprod Immunol 63: 17-21

Eastabrook G, Hu Y \& von Dadelszen P (2008) The role of decidual natural killer cells in normal placentation and in the pathogenesis of preeclampsia. J Obstet Gynaecol Can. 30:467-76.

Engel SA, Erichsen HC, Savitz DA, Thorp J, Chanock SJ \& Olshan AF (2005) Risk of spontaneous preterm birth is associated with common proinflammatory cytokine polymorphisms. Epidemiology 16:469-77.

Fest S, Aldo PB, Abrahams VM, Visintin I, Alvero A, Chen R, Chavez SL, Romero R \& Mor $\mathrm{G}$ (2007) Trophoblast-macrophage interactions: a regulatory network for the protection of pregnancy. Am J Reprod Immunol.57:55-66.

Fingerle-Rowson G, Petrenko O, Metz CN, Forsthuber TG, Mitchell R, Huss R, Moll U, Müller W \& Bucala R (2003) The p53-dependent effects of macrophage migration inhibitory factor revealed by gene targeting. Proc Natl Acad Sci U S A. 100:9354-9

Fonseca L, Ramin SM, Mele L, Wapner RJ, Johnson F, Peaceman AM, Sorokin Y, Dudley DJ, Spong CY, Leveno KJ, Caritis SN, Miodovnik M, Mercer B, Thorp JM, O'sullivan MJ, Carpenter MW, Rouse DJ \& Sibai B; Eunice Kennedy Shriver National Institute of Child 
Health and Human Development (NICHD) Maternal Fetal Medicine Units Network (MFMU) (2009) Bone metabolism in fetuses of pregnant women exposed to single and multiple courses of corticosteroids. Obstet Gynecol. 114:38-44

Furukawa S, Usuda K, Abe M \& Ogawa I (2004) Histopathological findings of cleft palate in rat embryos induced by triamcinolone acetonide. J Vet Med Sci 66:397-402

Gaillard R, Riondel A, Muller A, Herrmann W \& Baulieu EE (1984) RU 486: A steroid with antiglucocorticosteroid activity that only disinhibits the human pituitary-adrenal system at a specific time of day. Proc Natl Acad Sci USA 81:3879-3882

Garfield RE, Blennerhasset MG \& Miller SM (1988) Control of myometrial contractility: role and regulation of gap-junctions. Oxf Rev Reprod Biol 10:436-90

Gesina E, Blondeau B, Milet A, Le Nin I, Duchene B, Czernichow P, Scharfmann R, Tronche F \& Breant B (2006) Glucocorticoid signalling affects pancreatic development through both direct and indirect effects, Diabetologia 49:2939-2947

Gibbs RS, Romero R, Hiller SL, Eschenbach DA, Sweet RL (1992) A review of premature birth and subclinical infection. Am J obstet Gynecol 166. 1515-28

Gopichandran N, Ekbote UV, Walker JJ, Brooke D \& Orsi NM (2006) Multiplex determination of murine seminal fluid cytokine profiles. Reproduction 131: 613-21

Grimes DA (1997) Medical abortion in early pregnancy: a review of the evidence. Obstet Gynecol 89:790-6

Grivell R, Dodd J \& Robinson J (2009) The prevention and treatment of intrauterine growth restriction. Best Pract Res Clin Obstet Gynaecol. 2009 23:795-807

Guerin LR, Prins JR \& Robertson SA (2009) Regulatory T-cells and immune tolerance in pregnancy: a new target for infertility treatment? Hum Reprod Update 15:517-35.

Guller S, Kong L, Wozniak R \& Lockwood CJ (1995) Reduction of extracellular matrix protein expression in human amnion epithelial cells by glucocorticoids: a potential role in preterm rupture of the fetal membranes. J Clin Endocrinol Metab. 80:2244-50.

Gur C, Diav-Citrin O, Shechtman S, Arnon J \& Ornoy A (2004) Pregnancy outcome after first trimester exposure to corticosteroids: a prospective controlled study. Reprod Toxicol 18: 93-101

Guyatt GH, Akl EA, Crowther M, Gutterman DD \& Schuünemann HJ; American College of Chest Physicians Antithrombotic Therapy and Prevention of Thrombosis Panel. (2012) Executive summary: Antithrombotic Therapy and Prevention of Thrombosis, 9th ed: American College of Chest Physicians Evidence-Based Clinical Practice Guidelines. Chest 141(2 Suppl):7S-47S

Haas DM \& Ramsey PS (2008) Progestogen for preventing miscarriage. Cochrane Database Syst Rev (2):CD003511

Heikinheimo O, Raivio T, Honkanen H, Ranta S \& Jänne OA.Termination of pregnancy with mifepristone and prostaglandin suppresses transiently circulating glucocorticoid bioactivity. J Clin Endocrinol Metab. 88:323-6

Hill DJ \& Duvillie B (2000) Pancreatic development and adult diabetes. Pediatr. Res.48:269274

Hirata T, Osuga Y, Hamasaki K, Hirota Y, Nose E, Morimoto C, Harada M, Takemura Y, Koga K, Yoshino O, Tajima T, Hasegawa A, Yano T \& Taketani Y (2007) Expression of 
toll-like receptors 2, 3, 4, and 9 genes in the human endometrium during the menstrual cycle. J Reprod Immunol. 74: 53-60

Huang HY, Chan SH, Wu CH, Wang CW, Lai CH \& Soong YK (2005) Interleukin-1 system messenger ribonucleic acid and protein expression in human fallopian tube may be associated with ectopic pregnancy. Fertil Steril.84:1484-92.

Ietta F, Todros T, Ticconi C, Piccoli E, Zicari A, Piccione E \& Paulesu L (2002) Macrophage migration inhibitory factor in human pregnancy and labor. Am J Reprod Immunol. 48:404-9.

Ietta F, Wu Y, Romagnoli R, Soleymanlou N, Orsini B, Zamudio S, Paulesu L \& Caniggia I (2007) Oxygen regulation of macrophage migration inhibitory factor in human placenta. Am J Physiol Endocrinol Metab. 292:E272-80.

Ietta F, Bechi N, Romagnoli R, Bhattacharjee J, Realacci M, Di Vito M, Ferretti C \& Paulesu L (2010) 17 $\beta$-Estradiol modulates the macrophage migration inhibitory factor secretory pathway by regulating ABCA1 expression in human first-trimester placenta.Am J Physiol Endocrinol Metab. 298:E411-8

Jauniaux E, Gulbis B, Schandene L, Collette J \& Hustin J (1996) Distribution of interleukin-6 in maternal and embryonic tissues during the first trimester. Mol Hum Reprod 2:239-43.

Jin LP, Chen QY, Zhang T, Guo PF, Li DJ. The CD4+CD25 bright regulatory T cells and CTLA-4 expression in peripheral and decidual lymphocytes are down-regulated in human miscarriage. Clin Immunol. 2009 Dec;133(3):402-10.

Kajantie E, Raivio T, Janne OA, Hovi P, Dunkel L \& Andersson S (2004) Circulating glucocorticoid bioactivity in the preterm newborn after antenatal betamethasone treatment. J Clin Endocrinol Metab 89:3999-4003

Karagouni EE, Chryssikopoulos A, Mantzavinos T, Kanakas N \& Dotsika EN (1998) Interleukin-1beta and interleukin-1alpha may affect the implantation rate of patients undergoing in vitro fertilization-embryo transfer. Fertil Steril. 70:553-9.

Kibschull M, Gellhaus A \& Winterhager E. (2008). Analogous and unique functions of connexins in mouse and human placental development. Placenta 29, 848-854. doi:10.1016/J.PLACENTA.2008.07.013

King J \& Flenady V (2002) Prophylactic antibiotics for inhibiting preterm labour with intact membranes. Cochrane Database Syst Rev 4:CD000246

King J, Flenady V, Cole S, Thornton S (2005) Cyclo-oxygenase (COX) inhibitors for treating preterm labour. Cochrane Database Syst Rev (2):CD001992.

Kirshbaum T (1993)Antibiotics in the treatment of preterm labor. Am J Obstet Gynecol 16 1239-46

Knackstedt M, Ding JW, Arck PC, Hertwig K, Coulam CB, August C, Lea R, Dudenhausen JW, Gorczynski RM, Levy GA \& Clark DA (2001) Activation of the novel prothrombinase, $\mathrm{fg} 12$, as a basis for the pregnancy complications spontaneous abortion and pre-eclampsia. Am J Reprod Immunol. 46:196-210.

Korakaki E, Gourgiotis D, Aligizakis A, Manoura A, Hatzidaki E, Giahnakis E, Marmarinos A, Kalmanti M \& Giannakopoulou C (2007) Levels of bone collagen markers in preterm infants: relation to antenatal glucocorticoid treatment. J Bone Miner Metab 25:172-178 
Krassas GE, Poppe K \& Glinoer D (2010) Thyroid function and human reproductive health.Endocr Rev 31:702-55

Kumar P \& Seshadri R. Neonatal morbidity and growth in very low birth-weight infants after multiple courses of antenatal steroids. J Perinatol 25:698-702.

Kwak-Kim JY, Chung-Bang HS, Ng SC, Ntrivalas EI, Mangubat CP, Beaman KD, Beer AE \& Gilman-Sachs A (2003) Increased T helper 1 cytokine responses by circulating $T$ cells are present in women with recurrent pregnancy losses and in infertile women with multiple implantation failures after IVF. Hum Reprod.18:767-73.

Kwak-Kim J, Park JC, Ahn HK, Kim JW \& Gilman-Sachs A (2010) Immunological modes of pregnancy loss. Am J Reprod Immunol. 63:611-23.

Laird SM, Tuckerman EM, Cork BA, Linjawi S, Blakemore AI \& Li TC (2003) A review of immune cells and molecules in women with recurrent miscarriage. Hum Reprod Update 9:163-74

Lee SE, Romero R, Park CW, Jun JK \& Yoon BH (2008) The frequency and significance of intraamniotic inflammation in patients with cervical insufficiency. Am J Obstet Gynecol 198:633.e1-8

Leonhardt SA \& Edwards DP (2002) Mechanism of action of progesterone antagonists. Exp Biol Med 227:969-80

Li W, Gao L, Wang Y, Duan T, Myatt L \& Sun K (2006) Enhancement of cortisol-induced 11beta-hydroxysteroid dehydrogenase type 1 expression by interleukin 1beta in cultured human chorionic trophoblast cells. Endocrinology 147: 2490-5.

Liu J \& Feng ZC (2010) Increased umbilical cord plasma interleukin-1 beta levels was correlated with adverse outcomes of neonatal hypoxic-ischemic encephalopathy. J Trop Pediatr. 56:178-82

Lucovnik M, Kuon RJ, Chambliss LR, Maner WL, Shi SQ, Shi L, Balducci J \& Garfield RE (2011) Progestin treatment for the prevention of preterm birth. Acta Obstet Gynecol Scand. 90:1057-69

Lunghi L, Pavan B, Biondi C, Paolillo R, Valerio A, Vesce F \& Patella A (2010) Use of glucocorticoids in pregnancy. Curr Pharm Des. 16:3616-37.

Malassine' A \& Cronier L. (2005). Involvement of gap junctions in placental functions and development. Biochim. Biophys. Acta 1719:117-124.

Masuhiro K, Matsuzaki N, Nishino E, Taniguchi T, Kameda T, Li Y, Saji F \& Tanizawa O (1991) Trophoblast-derived interleukin-1 (IL-1) stimulates the release of human chorionic gonadotropin by activating IL-6 and IL-6-receptor system in first trimester human trophoblasts. J Clin Endocrinol Metab.72:594-601.

McDonald HM, Brocklehurst P \& Gordon A (2007) Antibiotics for treating bacterial vaginosis in pregnancy. Cochrane Database Syst Rev 1:CD000262;

McNeil CJ, Nwagwu MO, Finch AM, Page KR, Thain A, McArdle HJ \& Ashworth CJ. (2007) Glucocorticoid exposure and tissue gene expression of 11beta HSD-1, 11beta HSD-2, and glucocorticoid receptor in a porcine model of differential fetal growth. Reproduction 133: 653-61

Michael AE \& Papageorghiou AT (2008) Potential significance of physiological and pharmacological glucocorticoids in early pregnancy. Hum Reprod Update 14:497-517 
Minas V, Loutradis D \& Makrigiannakis A (2005) Factors controlling blastocyst implantation. Reprod Biomed Online. 10:205-16.

Mitanchez D (2010) Fetal and neonatal complications of gestational diabetes: perinatal mortality, congenital malformations, macrosomia, shoulder dystocia, birth injuries, neonatal outcomes. J Gynecol Obstet Biol Reprod (Paris). 39:S189-99

Mitsunari M, Yoshida S, Shoji T, Tsukihara S, Iwabe T, Harada T \& Terakawa N (2006) Macrophage-activating lipopeptide-2 induces cyclooxygenase-2 and prostaglandin E(2) via toll-like receptor 2 in human placental trophoblast cells. J Reprod Immunol 72:46-59

Murphy VE, Zakar T, Smith R, Giles WB, Gibson PG \& Clifton VL (2002) Reduced 11ßhydroxysteroid dehydrogenase type 2 activity is associated with decreased birth weight centile in pregnancies complicated by asthma. J Clin Endocrinol Metab 87:1660-1668

Murphy VE \& Gibson PG (2011) Asthma in pregnancy. Clin Chest Med.32:93-110

Mwaniki MK, Atieno M, Lawn JE \& Newton CR (2012) Long-term neurodevelopmental outcomes after intrauterine and neonatal insults: a systematic review. Lancet. 379:445-52

Nath CA, Ananth CV, Smulian JC, Shen-Schwarz S \& Kaminsky L (2007) Histologic evidence of inflammation and risk of placental abruption. Am J Obstet Gynecol.197:319.e1-6.

Nielsen HS, Steffensen R, Varming K, Van Halteren AG, Spierings E, Ryder LP, Goulmy E \& Christiansen OB (2009) Association of HY-restricting HLA class II alleles with pregnancy outcome in patients with recurrent miscarriage subsequent to a firstborn boy. Hum Mol Genet 18:1684-1691

Nishimura T, Dunk C, Lu Y, Feng X, Gellhaus A, Winterhager E, Rossant J \& Lye SJ. (2004). Gap junctions are required for trophoblast proliferation in early human placental development. Placenta 25, 595-607. doi:10.1016/J.PLACENTA.2004.01.002

Norman JE, Kelly RW \& Baird DT (1991) Uterine activity and decidual prostaglandin production in women in early pregnancy in response to mifepristone with or without indomethacin in vivo. Hum Reprod 6:740-4

Nyirenda MJ, Lindsay RS, Kenyon, Burchell A \& Seckl JR (1998) Glucocorticoid exposure in late gestation permanently programs rat hepatic phosphoenolpyruvate carboxykinase and glucocorticoid receptor expression and causes glucose intolerance in adult offspring, J. Clin. Invest. 101:2174-2181

Nyirenda MJ, Carter R, Tang JI, de Vries A, Schlumbohm C, Hillier SG, Streit F, Oellerich M, Armstrong VW, Fuchs E \& Seckl JR. (2009) Prenatal programming of metabolic syndrome in the common marmoset is associated with increased expression of 11betahydroxysteroid dehydrogenase type 1, Diabetes 58:2873-2879

Parker Jr CR, AtkinsonMW,Owen J \& AndrewsWW (1996) Dynamics of the fetal adrenal, cholesterol, and apolipoprotein B responses to antenatal betamethasone therapy. Am J Obstet Gynecol 174:562-565

Pattison NS, Chamley LW, Birdsall M, Zanderigo AM, Liddell HS \& McDougall J (2000) Does aspirin have a role in improving pregnancy outcome for women with the antiphospholipid syndrome? A randomized controlled trial. Am J Obstet Gynecol 183: 1008-12 
Paulesu L, Bhattacharjee J, Bechi N, Romagnoli R, Jantra S \& Ietta F (2010) Pro-inflammatory cytokines in animal and human gestation. Curr Pharm Des. 16:3601-15

Peck A \& Mellins ED (2010) Plasticity of T-cell phenotype and function: the T helper type 17 example. Immunology. 129:147-53.

Pei K, Yu C, Shi X \& Jia M (2010) The effects of mifepristone on the expressions of osteopontin, interleukin- 6 and leukemia inhibitory factor in the villi of early pregnant women. Contraception. 82:379-84

Pellicer A, Dominguez F, Remohi J \& Simón C (2002) Molecular basis of implantation. Reprod Biomed Online. 5:44-51. J Reprod Immunol. 72:46-59.

Pioli PA, Weaver LK, Schaefer TM, Wright JA, Wira CR \& Guyre PM (2006) Lipopolysaccharide-induced IL-1 beta production by human uterine macrophages upregulates uterine epithelial cell expression of human beta-defensin 2. J Immunol 176: 6647-55

Quenby S, Bates M, Doig T, Brewster J, Lewis-Jones DI, Johnson PM \& Vince G (1999) Preimplantation endometrial leukocytes in women with recurrent miscarriage. Hum Reprod 14:2386-2391

Quenby S, Farquharson R, Young M \& Vince G (2003) Successful pregnancy outcome following 19 consecutive miscarriages: case report. Hum Reprod. 18:2562-4.

Quenby S, Kalumbi C, Bates M, Farquharson R \& Vince G (2005) Prednisolone reduces preconceptual endometrial natural killer cells in women with recurrent miscarriage. Fertil Steril. 84:980-4.

Radysh TV \& Chernyshov VP (2005) Immunopathophysiologic characteristics of early pregnancy in women with recurrent miscarriage. Fiziol Zh. 51:65-72.

Raghupathy R, Makhseed M, Azizieh F, Omu A, Gupta M \& Farhat R (2000) Cytokine production by maternal lymphocytes during normal human pregnancy and in unexplained recurrent spontaneous abortion. Hum Reprod 15:713-718

Raghupathy R, Al Mutawa E, Makhseed M, Azizieh F \& Szekeres-Bartho J (2005) Modulation of cytokine production by dydrogesterone in lymphocytes from women with recurrent miscarriage. BJOG. 112:1096-101.

Raghupathy R, Al-Mutawa E, Al-Azemi M, Makhseed M, Azizieh F \& Szekeres-Bartho J (2009) Progesterone-induced blocking factor (PIBF) modulates cytokine production by lymphocytes from women with recurrent miscarriage or preterm delivery. JReprod Immunol 80:91-9

Rahimi R, Nikfar S \& Abdollahi M (2006) Meta-analysis finds use of inhaled corticosteroids during pregnancy safe: a systematic meta-analysis review. Hum Exp Toxicol. 25:447-52.

Rai R, Backos M, Baxter N, Chilcott I, Regan L. Recurrent miscarriage - an aspirin a day? Hum Reprod 2000; 15: 2220-3

Rai R \& Regan L (2006) Recurrent miscarriage. Lancet 368:601-1

Renaud SJ, Cotechini T, Quirt JS, Macdonald-Goodfellow SK, Othman M, Graham CH. Spontaneous pregnancy loss mediated by abnormal maternal inflammation in rats is linked to deficient uteroplacental perfusion. J Immunol. 2011 Feb 1;186(3):1799-808. 
Robb L, Li R, Hartley L, Nandurkar HH, Koentgen F \& Begley CG (1998) Infertility in female mice lacking the receptor for interleukin 11 is due to a defective uterine response to implantation. Nat Med 4: 303-8

Romero R, Gomez R, Ghezzi F, Bo Hyun Yoon, Mazor M, Edwin SS \& Berry SM (1998) A fetal systemic inflammatory response is followed by the spontaneous onset of preterm parturition. Am J Obstet Gynecol 179:186-93.

Romero R, Chaiworapongsa T, Espinoza J, Gomez R, Yoon BH, Edwin S, Mazor M, Maymon E \& Berry S (2002) Fetal plasma MMP-9 concentrations are elevated in preterm premature rupture of the membranes. Am J Obstet Gynecol 187:1125-30

Ryu JS, Majeska RJ, Ma Y, LaChapelle L \& Guller S (1999) Steroid regulation of human placental integrins: suppression of alpha2 integrin expression in cytotrophoblasts by glucocorticoids. Endocrinology. 140:3904-8

Rushton DI (1988) Placental pathology in spontaneous miscarriage. In: Beard RW, Sharp F, eds. Early Pregnancy Loss: Mechanisms and Treatment. London: Royal College of Obstetricians and Gynaecologists : 149-58

Saini V, Arora S, Yadav A \& Bhattacharjee J (2011) Cytokines in recurrent pregnancy loss. Clin Chim Acta.412:702-8

Saito S, Nishikawa K, Morii T, Enomoto M, Narita N, Motoyoshi K \& Ichijo M (1993) Cytokine production by CD16-CD56bright natural killer cells in the human early pregnancy decidua. Int Immunol. 5:559-63

Salgado A, Bóveda JL, Monasterio J, Segura RM, Mourelle M, Gómez-Jiménez J \& Peracaula R (1994) Inflammatory mediators and their influence on haemostasis. Haemostasis 24:132-8

Salmon JE \& Girardi G (2008) Antiphospholipid antibodies and pregnancy loss: a disorder of inflammation. J Reprod Immunol. 77:51-6.

Santoni A, Carlino C \& Gismondi A (2008) Uterine NK cell development, migration and function. Reprod Biomed Online 16:202-10

Schaefer TM, Fahey JV, Wright JA \& Wira CR (2005) Innate immunity in the human female reproductive tract: antiviral response of uterine epithelial cells to the TLR3 agonist poly (I:C). J Immunol 174: 992-1002

Schraufstatter IU, Trieu K, Zhao M, Rose DM, Terkeltaub RA \& Burger M (2003) IL- 8mediated cell migration in endothelial cells depends on cathepsin B activity and transactivation of the epidermal growth factor receptor. J Immunol 171: 6714-22

Scott JR (2003) Immunotherapy for recurrent miscarriage. Cochrane Database Syst Rev 1:CD000112

Seckl JR (2004) Prenatal glucocorticoids and long-term programming, Eur. J. Endocrinol 151:49-62

Seckl JR \& Holmes MC (2007)Mechanisms of Disease: glucocorticoids, their placental metabolism and fetal 'programming' of adult pathophysiology. Nature Clinical Practice Endocrinology \& Metabolism 3:479-88.

Shynlova O, Tsui P, Jaffer S \& Lye SJ (2009) Integration of endocrine and mechanical signals in the regulation of myometrial functions during pregnancy and labour. Eur J Obstet Gynecol Reprod Biol 144 Suppl 1:S2-10 
Simcox R, Sin WT, Seed PT, Briley A \& Shennan AH (2007) Prophylactic antibiotics for the prevention of preterm birth in women at risk: a meta-analysis. Aust N Z J Obstet Gynaecol 47:368-77.

Sljivic S, Kamenov B, Maglajlic S, Djordjevic V, Stojkovic-Eferica I, Stojanovic M, Stefanovic M, Mihailovic D, Mrkaic L \& Tasic G (2006) Possible interactions of genetic and immuno-neuro-endocrine regulatory mechanisms in pathogenesis of congenital anomalies. Med Hypotheses. 67:57-64.

Sotiriadis A, Makrydimas G, Papatheodorou S \& Ioannidis JP (2009) Corticosteroids for preventing neonatal respiratory morbidity after elective caesarean section at term. Cochrane Database Syst Rev. CD006614

Spinillo A, Beneventi F, Ramoni V, Caporali R, Locatelli E, Simonetta M, Cavagnoli C, Alpini C, Albonico G, Prisco E \& Montecucco C. (2012) Prevalence and significance of previously undiagnosed rheumatic diseases in pregnancy. Ann Rheum Dis. In press

Stephenson MD, Kutte WH, Purkiss S, Librach C, Schultz P, Houlihan E \& Liao C (2010) Intravenous immunoglobulin and idiopathic secondary recurrent miscarriage: a multicentered randomized placebo-controlled trial, Human Reproduction 25:2203-2209

Suffee N, Richard B, Hlawaty H, Oudar O, Charnaux N \& Sutton A (2011) Angiogenic properties of the chemokine RANTES/CCL5. Biochem Soc Trans 39:1649-53.

Sun K, Ma R, Cui X, Campos B, Webster R, Brockman D \& Myatt L (2003) Glucocorticoids induce cytosolic phospholipase A2 and prostaglandin $\mathrm{H}$ synthase type 2 but not microsomal and cytosolic prostaglandin E synthase (PGES) expression in cultured primary human amnion cells. J Clin Endocrinol Metab 88: 5564-71.

Swolin-Eide D, Dahlgren J, Nilsson C, Albertsson Wikland K, Holmäng A \& Ohlsson C. Affected skeletal growth but normal bone mineralization in rat offspring after prenatal dexamethasone exposure. J Endocrinol. 174:411-8.

Swyer GI, Daley D. Progesterone implantation in habitual abortion. BMJ 1953;1:1073-7

Tang AW, Alfirevic Z, Turner MA, Drury J \& Quenby S. (2009) Prednisolone Trial: Study protocol for a randomised controlled trial of prednisolone for women with idiopathic recurrent miscarriage and raised levels of uterine natural killer (uNK) cells in the endometrium. Trials. 10;10:102

Thinkhamrop J, Hofmeyr GJ, Adetoro O \& Lumbiganon P (2002) Prophylactic antibiotic administration in pregnancy to prevent infectious morbidity and mortality. Cochrane Database Syst Rev 4:CD002250

Thuere C, Zenclussen ML, Schumacher A, Langwisch S, Schulte-Wrede U, Teles A, Paeschke S, Volk HD \& Zenclussen AC (2007) Kinetics of regulatory T cells during murine pregnancy. Am J Reprod Immunol. 58:514-23

Thum MY, Bhaskaran S, Abdalla HI, Ford B, Sumar N \& Bansa (2008) Prednisolone suppresses NK cell cytotoxicity in vitro in women with a history of infertility and elevated NK cell cytotoxicity. 1 A.Am J Reprod Immunol. 59:259-65

Tincani A, Cavazzana I, Ziglioli T, Lojacono A, De Angelis V \& Meroni P (2010) Complement activation and pregnancy failure. Clin Rev Allergy Immunol. 39:153-9 
Tsuzuki Y, Takeba Y, Kumai T, Matsumoto N, Mizuno M, Murano K, Asoh K, Takagi M, Yamamoto H \& Kobayashi S (2009) Antenatal glucocorticoid therapy increase cardiac alpha-enolase levels in fetus and neonate rats. Life Sci 85:609-16.

Verhoog NJ, Du Toit A, Avenant C \& Hapgood JP (2011) Glucocorticoid-independent repression of tumor necrosis factor (TNF) alpha-stimulated interleukin (IL)-6 expression by the glucocorticoid receptor: a potential mechanism for protection against an excessive inflammatory response. J Biol Chem 286:19297-310.

Vesce F, Pareschi MC, Travagli S, Tarabbia C, Pansini F, Salvatorelli G, Gulinati AM, Grandi E \& Biondi C (1992) Betamethasone-induced lecithin release in vitro from the fetal membranes. Gynecol Obstet Invest. 33:134-7

Vesce F, Farina A, Jorizzo G, Tarabbia C, Calabrese O, Pelizzola D \& Giovannini G, Piffanelli A (1996) Raised level of amniotic endothelin in pregnancies with fetal aneuploidy. Fetal Diagn Ther. 11:94-8.

Vesce F, Farina A, Giorgetti M, Jorizzo G, Bianciotto A, Calabrese O \& Mollica G (1997) Increased incidence of preeclampsia in pregnancies complicated by fetal malformation. Gynecol Obstet Invest. 44:107-11.

Vesce F, Buzzi M, Ferretti ME, Pavan B, Bianciotto A, Jorizzo G \& Biondi C (1998) Inhibition of amniotic prostaglandin E release by ampicillin. Am J Obstet Gynecol 178: 759-64

Vesce F, Pavan B, Buzzi M, Pareschi MC, Bianciotto A, Iorizzo G \& Biondi C (1999) Effect of different classes of antibiotics on amniotic prostaglandin E release. Prostaglandins Other Lipid Mediat. 57:207-18

Vesce F, Scapoli C, Giovannini G, Piffanelli A, Geurts-Moespot A \& Sweep FC (2001) Plasminogen activator system in serum and amniotic fluid of euploid and aneuploid pregnancies. Obstet Gynecol. 97:404-8.

Vesce F, Scapoli C, Giovannini G, Tralli L, Gotti G, Valerio A \& Piffanelli A (2002) Cytokine imbalance in pregnancies with fetal chromosomal abnormalities. Hum Reprod. 17:803-8

Vesce F, Pavan B, Lunghi L, Giovannini G, Scapoli C, Piffanelli A \&Biondi C (2004) Inhibition of amniotic Interleukin-6 and Prostaglandin E2 release by ampicillin Obstet Gynecol 103: 108-113

von Eye Corleta H (2010) It is time to respect the American Society for Reproductive Medicine definition of recurrent pregnancy loss. Fertil Steril 94(4):e61

Wang ZC, Yunis EJ, De los Santos MJ, Xiao L, Anderson DJ \& Hill JA (2002) T helper 1-type immunity to trophoblast antigens in women with a history of recurrent pregnancy loss is associated with polymorphism of the IL1B promoter region. Genes Immun. 3:38-42

Wang WJ, Hao CF, Yi-Lin, Yin GJ, Bao SH, Qiu LH \& Lin QD (2010) Increased prevalence of $\mathrm{T}$ helper 17 (Th17) cells in peripheral blood and decidua in unexplained recurrent spontaneous abortion patients. J Reprod Immunol. 84:164-70.

Wang D, Lin W, Pan Y, Kuang X, Qi X \& Sun H (2011) Chronic blockade of glucocorticoid receptors by RU486 enhances lipopolysaccharide-induced depressive-like behaviour and cytokine production in rats. Brain Behav Immun. 25:706-14

Waterman WR, Xu LL, Tetradis S, Motyckova G, Tsukada J, Saito K, Webb AC, Robinson DR \& Auron PE (2006) Glucocorticoid inhibits the human pro-interleukin lbeta gene 
(ILIB) by decreasing DNA binding of transactivators to the signal-responsive enhancer. Mol Immunol 43:773-82

Wegmann TG, Lin H, Guilbert L \& Mosmann TR (1993) Bidirectional cytokine interactions in the maternal-fetal relationship: is successful pregnancy a TH2 phenomenon? Immunol Today 14:353-356

Wells C N (1953) Treatment of hyperemesis gravidarum with cortisone. Am J Obstet Gynecol 66:598-601

White CA, Robb L \& Salamonsen LA (2004) Uterine extracellular matrix components are altered during defective decidualization in interleukin-11 receptor alpha deficient mice. Reprod Biol Endocrinol 2: 76

Williams PJ, Bulmer JN, Searle RF, Innes BA \& Robson SC (2009) Altered decidual leucocyte populations in the placental bed in pre-eclampsia and foetal growth restriction: a comparison with late normal pregnancy. Reproduction. 138:177-84

Wira CR, Fahey JV, Ghosh M, Patel MV, Hickey DK \& Ochiel DO (2010) Sex hormone regulation of innate immunity in the female reproductive tract: the role of epithelial cells in balancing reproductive potential with protection against sexually transmitted pathogens. Am J Reprod Immunol 63: 544-65

Winterhager E, Von Ostau C, Gerke M, Gruemmer R, Traub O \& Kaufmann P. (1999). Connexin expression patterns in human trophoblast cells during placental development. Placenta 20, 627-638. doi:10.1053/PLAC.1999.0434

Xu J, Treem WR, Roman C, Anderson V, Rubenstein R \& Schwarz SM (2011) Ileal immune dysregulation in necrotizing enterocolitis: role of CD40/CD40L in the pathogenesis of disease. J Pediatr Gastroenterol Nutr. 52:140-6.

Yamada H, Kato EH, Kobashi G, Ebina Y, Shimada S, Morikawa M, Sakuragi N \& Fujimoto S (2001) High NK cell activity in early pregnancy correlates with subsequent abortion with normal chromosomes in women with recurrent abortion. Am J Reprod Immunol. 46:132-6.

Yamada H, Kato EH, Morikawa M, Shimada S, Saito H, Watari M, Minakami H \& Nishihira J (2003) Decreased serum levels of macrophage migration inhibition factor in miscarriages with normal chromosome karyotype. Hum Reprod. 18:616-20.

Yang B, Trump RP, Shen Y, McNulty JA, Clifton LG, Stimpson SA, Lin P \& Pahel GL (2008) RU486 did not exacerbate cytokine release in mice challenged with LPS nor in $\mathrm{db} / \mathrm{db}$ mice. BMC Pharmacol.8:7 